\title{
Feasibility and acceptability of community health extension workers to identify and treat hypertension associated with pregnancy: Implementation research report
}

\author{
Emmanuel Nwala \\ Udochisom Anaba \\ Pooja Sripad \\ Population Council \\ Salisu Mohammed Ishaku \\ Population Council \\ Charlotte E. Warren \\ Population Council
}

Follow this and additional works at: https://knowledgecommons.popcouncil.org/departments_sbsr-rh

Part of the Community Health and Preventive Medicine Commons, Demography, Population, and Ecology Commons, Family, Life Course, and Society Commons, International Public Health Commons, Maternal and Child Health Commons, and the Medicine and Health Commons How does access to this work benefit you? Let us know!

\section{Recommended Citation}

Nwala, Emmanuel, Udochisom Anaba, Pooja Sripad, Salisu Mohammed Ishaku, and Charlotte E. Warren. 2019. "Feasibility and acceptability of community health extension workers to identify and treat hypertension associated with pregnancy: Implementation research report," Ending Eclampsia Endline Report. Washington, DC: Population Council. 


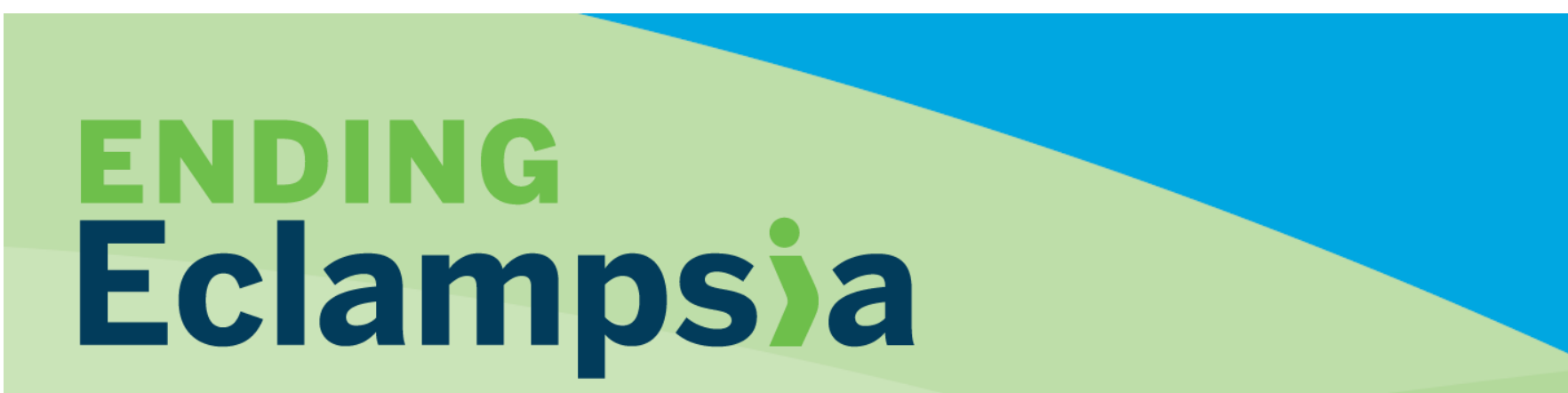

Feasibility and Acceptability of Community Health Extension Workers to Identify and Treat Hypertension Associated with Pregnancy: Implementation Research Report

\title{
March 2019
}

\author{
Emmanuel Nwala \\ Udochisom Anaba \\ Pooja Sripad \\ Salisu Ishaku \\ Charlotte Warren
}




\section{ENDING}

Ending Eclampsia seeks to expand access to proven, under-utilized interventions and commodities for the prevention, early detection, and treatment of pre-eclampsia and eclampsia and strengthen global partnerships. This research report is part of series of implementation research activities conducted by the Ending Eclampsia project in Nigeria and focuses on assessing the feasibility and acceptability of community health extension workers at the primary healthcare level to identify and treat pregnancy associated hypertension using Alpha Methyldopa (Aldomet).

\section{- POPULATION COUNCIL \\ Ideas. Evidence. Impact.}

The Population Council confronts critical health and development issues-from stopping the spread of HIV to improving reproductive health and ensuring that young people lead full and productive lives. Through biomedical, social science, and public health research in 50 countries, we work with our partners to deliver solutions that lead to more effective policies, programs, and technologies that improve lives around the world. Established in 1952 and headquartered in New York, the Council is a non-governmental, non-profit organization governed by an international board of trustees.

Population Council

4301 Connecticut Avenue NW, Suite 280

Washington DC, 20008

Tel: +1.877 .237 .9400$

www.popcouncil.org

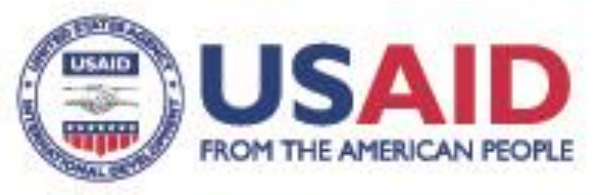

The Ending Eclampsia project is made possible by the generous support of the American people through the United States Agency for International Development (USAID) under the terms of USAID APS-OAA-A-1400048. The contents of this report are the sole responsibility of the Ending Eclampsia project and the Population Council and do not necessarily reflect the views of USAID or the United States Government.

(C) 2019 The Population Council, Inc. 


\section{TABLE OF CONTENTS}

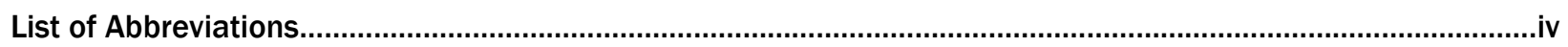

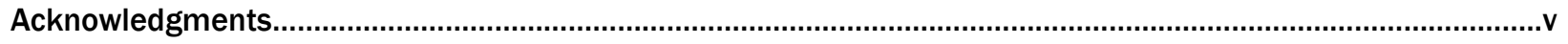

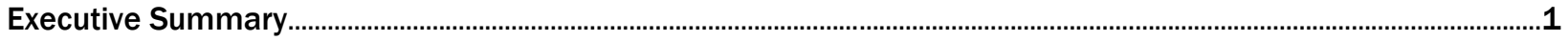

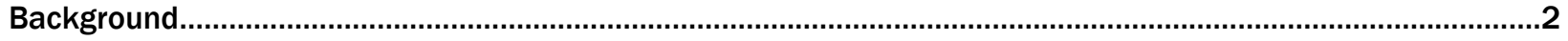

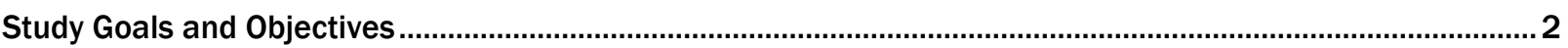

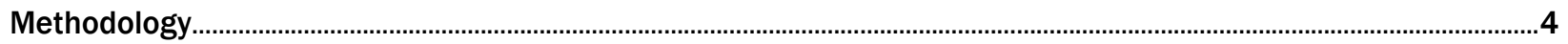

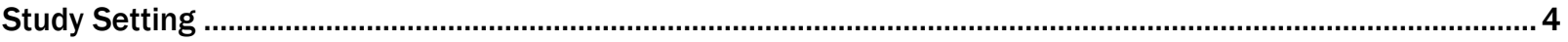

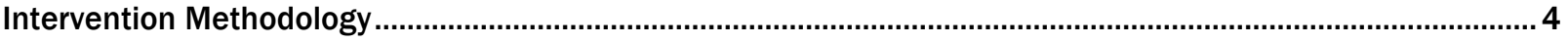

Facility Selection and CHEW Identification and Training..............................................................................4

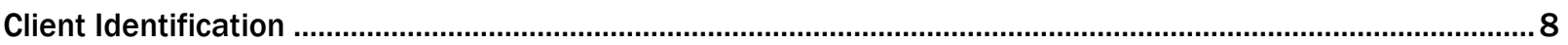

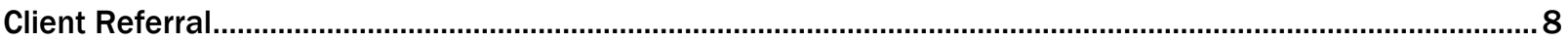

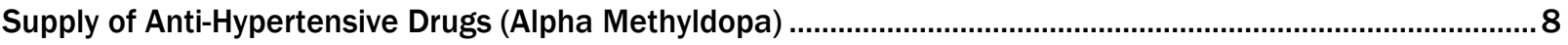

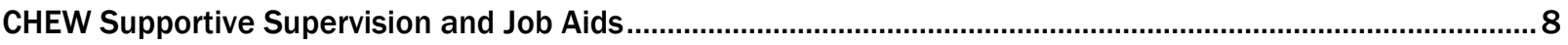

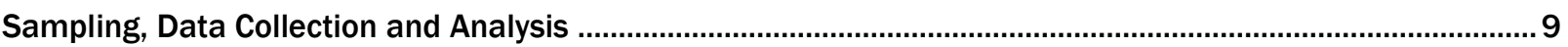

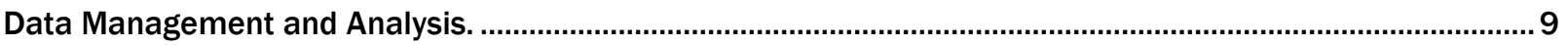

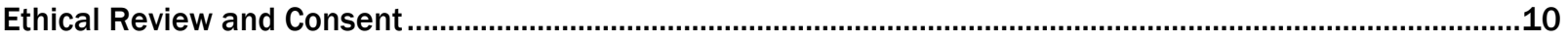

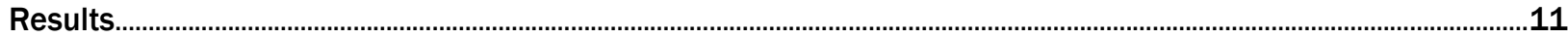

Management of Women with Hypertension in Pregnancy.........................................................................13

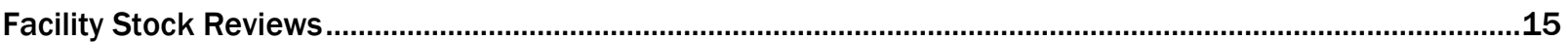

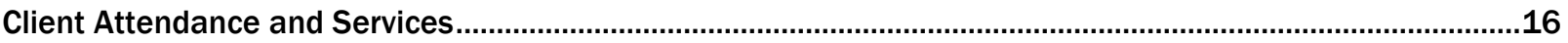

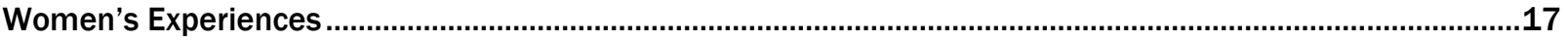

What Do Women Know About Hypertension in Pregnancy? ..............................................................................17

Women's Perceptions of the Content of Their Care ........................................................................................18

Women's Perceptions of Provider Prescription Habits, Commodity Supply and Follow Up Care .....................19

Women's Failure to Complete Referral Process...................................................................................................

Women's Perceptions of CHEWs' Care for Hypertensive Disorders ................................................................20

Late ANC Registration and Inconsistent Antenatal Care Impair Early Detection and Management of Hypertension in Pregnancy ..........................................................................................20

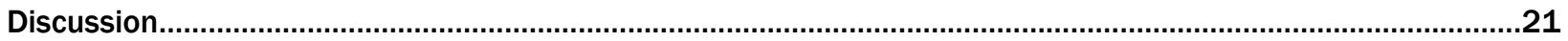

Conclusion

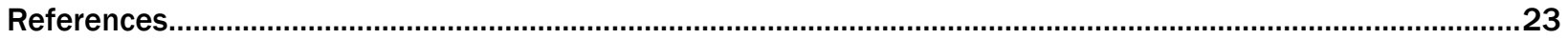




\section{LIST OF ACRONYMS}

$\begin{array}{ll}\text { ANC } & \text { Antenatal Care } \\ \text { BP } & \text { Blood Pressure } \\ \text { dBP } & \text { Diastolic Blood Pressure } \\ \text { SBP } & \text { Systolic Blood Pressure } \\ \text { CHEW } & \text { Community Health Extension Worker } \\ \text { CVA } & \text { Cerebrovascular Accident } \\ \text { FMoH } & \text { Federal Ministry of Health } \\ \text { HDP } & \text { Hypertensive Disorders in Pregnancy } \\ \text { JOHESU } & \text { Joint Health Sector Union } \\ \text { LGA } & \text { Local Government Area } \\ \text { LMIC } & \text { Low- and Middle Income Country } \\ \text { MgSO } 4 & \text { Magnesium Sulphate } \\ \text { MT } & \text { Master Trainer } \\ \text { NIE } & \text { Net Intervention Effect } \\ \text { NCH } & \text { National Council of Health } \\ \text { Ob/Gyn } & \text { Obstetrician and Gynecologist } \\ \text { PE } & \text { Pre-eclampsia } \\ \text { PE/E } & \text { Pre-eclampsia/Eclampsia } \\ \text { PHC } & \text { Primary Health Care } \\ \text { PHCUOR } & \text { Primary Health Care Under One Roof Policy } \\ \text { PNC } & \text { Postnatal Care } \\ \text { SMoH } & \text { State Ministry of Health } \\ \text { SPE } & \text { Severe Pre-Eclampsia } \\ \text { WHO } & \text { World Health Organization } \\ \text { USAID } & \text { United States Agency for International Development } \\ & \\ \text { OH }\end{array}$




\section{ACKNOWLEDGEMENTS}

This report is based on implementation research findings on assessing the feasibility and acceptability of Community Health Extension Workers at primary healthcare centers to identify and treat pregnancy associated hypertension using Alpha Methyldopa (Aldomet).

We acknowledge all stakeholders (professional associations and implementing partners) who provided valuable inputs during the study and dissemination of findings. The successful completion of this research would not have been possible without the enabling environment provided by the Federal Ministry of Health and of Ebonyi State Ministry of Health and the dedication of Community Health Extension Workers in the participating health facilities. We further acknowledge all the study participants, who gave their time and provided valuable information during the study. 


\section{EXECUTIVE SUMMARY}

Hypertensive disorders in pregnancy, experienced by 10 percent of women globally, are major contributors to maternal and newborn mortality, morbidity, and disability. Task shifting essential health services to mitigate insufficient human resources is recommended to strengthen and expand the health work force to rapidly increase access to quality services. Nigeria's task shifting policy recommends that community health extension workers administer a loading dose of magnesium sulphate prior to referral for severe preeclampsia or eclampsia to a higher level facility. The success achieved with magnesium sulphate task shifting to lower level health facilities has not been widely explored with anti-hypertensive drugs to control high blood pressure in pregnant women.

This study tested the feasibility and acceptability of community health extension workers at primary healthcare facilities in Ebonyi state to detect and manage pregnancy-associated hypertension using alpha methyldopa and magnesium sulphate where appropriate and refer for follow up. Baseline data were collected from 10 of 13 local government areas in 40 primary healthcare centers (20 interventions and 20 comparison) in 2016 and endline in November 2017.

In intervention arm only, community health extension workers were trained and mentored to detect, classify and manage hypertension associated with pregnancy, pre-eclampsia and eclampsia and refer to their affiliated secondary health facilities according to clinical protocols. For pregnant women identified with hypertension with or without significant proteinuria, they were recruited into the study and subsequently followed-up post-delivery. If a woman's blood pressure was not controlled, women were referred to a higher facility. For women with severe pre-eclampsia and eclampsia, they received a loading dose of magnesium sulphate and were referred.

Community health extension workers in the comparison arm received no training or mentorship; and continued with their usual practice of administering a loading dose of magnesium sulphate to women with severe pre-eclampsia/eclampsia and referral.

More community health extension workers in the intervention arm correctly identified normal blood pressure, and differentiated as well as managed, mild, moderate, and severe hypertension than those in the comparison arm. This included a 72 percent knowledge improvement in when to introduce antihypertensives versus a three percent improvement in the comparison arm; and were three times more likely to identify alpha methyldopa as a specific drug to control blood pressure at endline. Significant differences were also observed in knowledge and ability to categorize the various hypertensive disorders in pregnancy correctly. In both arms, community health extension workers were most likely to prescribe alpha methyldopa (60\% and 50\% respectively) at endline. Among women with moderate-to-severe hypertension who required anti-hypertensives upon diagnosis, more women in the intervention arm received treatment than women in the comparison arm.

During the study, five maternal deaths occurred: one intrapartum death from the intervention arm and four from the comparison arm (one antepartum, 2 intrapartum, one postpartum). The woman who died in the intervention arm did not receive a loading dose of Magnesium Sulphate following diagnosis of severe preeclampsia (all women who received a loading dose survived). A total of 13 fetal deaths also occurred: four in the intervention arm ( 3 stillbirths and one early neonatal death) and nine to the comparison arm (all stillbirths). None of the mothers of the babies who died received a loading dose of magnesium sulfate.

Community health extension workers at primary health care facilities can correctly measure blood pressure, detect abnormal blood pressure, and treat accordingly for severe pre-eclampsia and eclampsia, and refer to a higher facility for further management. Although challenges remain in ensuring sufficient commodities and supplies are continuously available, this study demonstrates how ministries of Health might use these missed opportunities to detect pre-eclampsia (and potentially other conditions) and prevent deterioration by providing anti-hypertensives and magnesium sulphate to stabilize and refer women. 


\section{BACKGROUND}

Hypertensive disorders in pregnancy (HDPs), experienced by 10 percent of women globally, are major contributors to maternal and newborn mortality, morbidity, and disability ${ }^{1-2}$. HDPs include pre-eclampsia, gestational hypertension (hypertension), and chronic hypertension during pregnancy. Pre-eclampsia, defined as hypertension with significant proteinuria after 20 weeks' gestation in pregnancy, complicates two to eight percent of pregnancies ${ }^{3,4}$. In low- and middle-income countries (LMICs), a woman is seven times more likely to develop pre-eclampsia than a woman in a high income country. Some 10 percent to 25 percent of women who suffer from pre-eclampsia likely will die ${ }^{5,6}$. About 10 percent of women with preeclampsia develop severe pre-eclampsia and eclampsia6-7. Of the 10 to 25 percent of the pre-eclampsia and eclampsia (PE/E)-related maternal deaths worldwide, eclampsia accounts for about 14 percent 5,8 .

In recent years, there has been increased recognition and support for the use of magnesium sulphate $\left(\mathrm{MgSO}_{4}\right)$ as a life-saving and cost-effective maternal health commodity, both as prophylaxis and treatment for convulsions due to severe $\mathrm{PE} / \mathrm{E}^{9-17}$. Similar attention has not been given to identifying and managing hypertension associated with $\mathrm{PE} / \mathrm{E}$, as well as other forms of hypertension seen in pregnancy. Failure to address hypertension minimizes the gains in institutionalizing $\mathrm{MgSO}_{4}$ in a health system for $\mathrm{PE} / \mathrm{E}$ management.

Globally, task shifting essential health services to accommodate insufficient human resources is recommended for strengthening and expanding health workforces for rapid increases in access to quality services ${ }^{18-19}$. Specific reorganization and decentralization recommended by the World Health Organization (WHO) is due to the knowledge that lower level cadres such as auxiliary nurse and midwives can administer, with targeted monitoring and evaluation (M\&E), anti-hypertensive drugs for severe HDP19. Less, however, is known about the abilities of community health extension workers-the main figures in primary health care (PHC) in Nigeria-and their suitability to provide anti-hypertensive services. CHEWs are a lower level service provider cadre with more training than an auxiliary nurse or midwife (as defined by WHO).

CHEWs in Nigeria receive three years of pre-service training and community experience, so it is conceivable they could also be provided with appropriate knowledge, skills, and training for managing moderate and severe hypertension using anti-hypertensive drugs recommended for use in pregnancy, and then referring women to higher levels for follow up care, if appropriate.

In Nigeria, HDPs-principally PE/E-account for over 23 percent of deaths among pregnant women ${ }^{6}$. Programs for averting PE/E mortality and morbidity have made $\mathrm{MgSO}_{4}$ routinely available, with some success $9,11,20$. These efforts have also implemented task shifting for $\mathrm{CHEW}$ administration of a loading dose of $\mathrm{MgSO}_{4}$ prior to referrals to a higher level facility for severe $\mathrm{PE} / \mathrm{E}{ }^{20-21}$. The successes achieved with $\mathrm{MgSO}_{4}$ task shifting to lower level health facilities has not been widely transferred to anti-hypertensive drugs for controlling high blood pressure (BP) in pregnant women prior to referral.

Rapidly increasing BP may result in cerebrovascular accident (CVA), a known cause of death in women with $\mathrm{PE} / \mathrm{E}$. Addressing HDP in a timely and effective way reduces maternal morbidity and mortality, but emphasis has varied on how to achieve this goal, with more attention to $\mathrm{MgSO}_{4}$ and less emphasis on studying the administration of anti-hypertensive drugs ${ }^{21}$. Before 2013 in Nigeria, CHEWs at PHCs were not authorized to administer $\mathrm{MgSO}_{4}$ for severe $\mathrm{PE} / \mathrm{E}$ due to perceptions of insufficient training22. A quasi-experimental pilot study in Kano state showed that $\mathrm{MgSO}_{4}$ task shifting (initial dose for women with severe $\mathrm{PE} / \mathrm{E}$, and referral to secondary hospitals) to CHEWs at PHCs resulted in demonstrable improvements in maternal and neonatal survival20. The study trained CHEWs, with one year of follow up, M\&E, and supportive supervision. Presentation of these findings at the 2012 National Council of Health (NCH) of Nigeria contributed to the policy change allowing CHEWs to administer a loading dose of $\mathrm{MgSO}_{4}$ prior to referral. 
Although HDP treatment by PHC CHEWs is not recommended in Nigeria's current national task shifting policy, a 2015 analysis in seven Nigerian states, of service providers' knowledge and practices, and pregnant women's and community members' understanding, of PE/E found that 41 percent of PHC providers (mainly CHEWs) reported prescribing anti-hypertensive drugs-some not recommended in pregnancy-to pregnant women ${ }^{23}$. It is imperative to provide appropriate anti-hypertensive drugs to pregnant women with moderate to severe HDP, and at their first contact with the health system.

CHEWs are currently not authorized to prescribe anti-hypertensive drugs but can refer pregnant women with high BP to a secondary hospital, although they may have the capacities to treat women on site 21 . This is contrary to other countries' practices and WHO recommendations for task shifting to lower level cadres ${ }^{18-}$ 19. This study tested the feasibility and acceptability of Nigeria's PHC CHEWs to detect and manage HDP using alpha methyldopa, including administration of $\mathrm{MgSO}_{4}$ and referral to higher level care, where appropriate.

\section{STUDY GOALS AND OBJECTIVES}

The overall aim of this study was to assess the feasibility and acceptability of CHEWs' detection and management of HDP using alpha methyldopa. The specific objectives were to:

- Assess the feasibility of CHEWs' detection and classification of high BP among pregnant women during antenatal care (ANC) contacts,

- Assess CHEWs' abilities to prescribe an anti-hypertensive drug (alpha methyldopa) for pregnant women with moderate hypertension, and

- Assess CHEWs' abilities to prescribe appropriate an anti-hypertensives drug (alpha methyldopa) for pregnant women with severe hypertension during $\mathrm{PE} / \mathrm{E}$ prior to referral, including prescribing and administering $\mathrm{MgSO}_{4}$ for severe PE/E prior to referral. 


\section{METHODOLOGY}

\section{STUDY SETTING}

This study was conducted in southeastern Nigeria's Ebonyi state, comprised of 13 local government areas (LGAs). Ebonyi is one of the three states where Population Council implemented the Ending Eclampsia project, a larger effort supporting $\mathrm{PE} / \mathrm{E}$ prevention, early detection, and management at lower health system levels ${ }^{23}$. Ebonyi has the worst health indices among Nigeria's southeastern states, similar to many northern states; but its level of education is generally higher than the north, which makes Ebonyi a conducive setting for this study.

\section{EBONYI STATE, NIGERIA}

- Total Population: 2.2 Million (2006 census)

- ANC attendance: $85 \%$

- Health facility deliveries: $60 \%$

- Postnatal care within $\mathbf{4 8}$ hours of delivery: $55 \%$

- Mean age at first delivery: 21.4

- Total fertility rate: $\mathbf{5 . 3}$

Nigeria's health system is designed for a secondary health care facility (i.e. hospital) in each LGA, to which four PHC facilities are referring facilities. Ebonyi state has 13 secondary hospitals and 52 PHC facilities. Statutorily, CHEWs staff all PHC facilities in Nigeria, including in Ebonyi state.

\section{HOW INTERVENTIONS WERE OPERATIONALIZED}

PHC CHEWs were trained and mentored by this study to detect, classify, and manage HDP, including referring patients to affiliated secondary hospitals. Hypertensive disorders investigated included chronic hypertension (defined as isolated hypertension diagnosed before the index pregnancy or detected before 20 weeks of gestation), gestational hypertension (isolated hypertension diagnosed for the first time after 20 weeks of index pregnancy without proteinuria), and pre-eclampsia (gestational hypertension and proteinuria of $\geq++$ using a urine dipstick). Hypertension was defined as a systolic BP (SBP) of $\geq 140 \mathrm{mmHg}$ and or diastolic BP (dBP) of $\geq 90 \mathrm{mmHg}$ measured on two different occasions, four to six hours apart. In some cases, where distance was a factor, clients stayed at the facility for repeat measurement; if clients lived nearby, they were instructed to return.

CHEWs were trained and mentored to correctly diagnose hypertension as chronic, gestational, or as PE/E. Training also featured hypertension classification-as mild, moderate, or severe-and either pre-eclampsia or severe pre-eclampsia. For mild hypertension, CHEWs were trained to only regularly monitor BP. For moderate hypertension, CHEWs prescribe alpha methyldopa. For severe hypertension, in addition to continued alpha methyldopa, CHEWs were advised to refer clients to a higher level facility, and if associated with severe pre-eclampsia, CHEWs administered a loading dose of $\mathrm{MgSO}_{4}$ before referral (see Table 1).

\section{FACILITY SELECTION AND CHEWS IDENTIFICATION AND TRAINING}

In collaboration with Ebonyi state's Ministry of Health (SMoH), Ending Eclampsia randomly selected 10 LGAs: five (featuring $20 \mathrm{PHC}$ facilities) to serve as intervention sites and the other five (also with $20 \mathrm{PHCs}$ ) as comparison sites. Both the intervention and comparison arms were already trained and authorized to administer a loading dose of $\mathrm{MgSO}_{4}$ for severe PE/E. CHEWs conducting antenatal care (ANC) services in the intervention arm were then also trained to detect and classify HDP, including treatment with alpha methyldopa and a loading dose of $\mathrm{MgSO}_{4}$, when appropriate. CHEWs in the comparison arm received no such training and mentorship, and were to continue usual practice, which includes administering a loading dose of $\mathrm{MgSO}_{4}$ to women with severe PE/E, as recommended by the national task shifting policy, for referring women with high BP during pregnancy. 
Table 1: Diagnostic and management algorithm used for this study

\begin{tabular}{|c|c|c|c|}
\hline Diagnosis & Categories & Interventions & Instructions \\
\hline \multirow{3}{*}{$\begin{array}{c}\text { Chronic } \\
\text { Hypertension }\end{array}$} & $\begin{array}{c}\text { Mild Hypertension } \\
(140-149 / 90-99 \mathrm{mmHg})\end{array}$ & $\begin{array}{l}\text { Monitor BP closely } \\
\text { No anti-hypertensive }\end{array}$ & $\begin{array}{l}\text { Return in one week or when } \\
\text { no complaint }\end{array}$ \\
\hline & $\begin{array}{c}\text { Moderate Hypertension } \\
(\geq 150 / 100 \mathrm{mmHg} \\
\text { but }<160 / 110 \mathrm{mmHg})\end{array}$ & $\begin{array}{l}\text { Introduce oral } \\
\text { methyldopa/Aldomet }\end{array}$ & $\begin{array}{c}\text { Return in one week or when } \\
\text { no complaint }\end{array}$ \\
\hline & $\begin{array}{c}\text { Severe Hypertension } \\
(\geq 160 / 110 \mathrm{mmHg})\end{array}$ & $\begin{array}{c}\text { Oral methyldopa/ } \\
\text { Aldomet }\end{array}$ & Refer to higher level facility \\
\hline \multirow{3}{*}{$\begin{array}{l}\text { Gestational } \\
\text { Hypertension }\end{array}$} & $140-149 / 90-99 \mathrm{mmHg}$ & $\begin{array}{l}\text { Monitor BP closely } \\
\text { No anti-hypertensive }\end{array}$ & $\begin{array}{l}\text { Return in one week or when } \\
\text { no complaint }\end{array}$ \\
\hline & $\begin{array}{c}\text { Moderate Hypertension } \\
(\geq 150 / 100 \mathrm{mmHg} \\
\text { But }<160 / 110 \mathrm{mmHg})\end{array}$ & $\begin{array}{l}\text { Introduce oral } \\
\text { methyldopa/Aldomet }\end{array}$ & $\begin{array}{c}\text { Return in one week or when } \\
\text { no complaint }\end{array}$ \\
\hline & $\begin{array}{c}\text { Severe Hypertension } \\
(\geq 160 / 110 \mathrm{mmHg})\end{array}$ & $\begin{array}{c}\text { Oral methyldopa/ } \\
\text { Aldomet }\end{array}$ & Refer to higher level facility \\
\hline \multirow{3}{*}{ Pre-eclampsia } & $\begin{array}{c}\text { Mild Hypertension } \\
(140-149 / 90-99 \mathrm{mmHg})\end{array}$ & $\begin{array}{c}\text { Monitor BP closely } \\
\text { No anti-hypertensive }\end{array}$ & $\begin{array}{c}\text { Return in one week or when } \\
\text { no complaint }\end{array}$ \\
\hline & $\begin{array}{c}\text { Moderate Hypertension } \\
(\geq 150 / 100 \mathrm{mmHg} \\
\text { But }<160 / 110 \mathrm{mmHg}) \\
\end{array}$ & $\begin{array}{l}\text { Introduce oral } \\
\text { methyldopa/Aldomet }\end{array}$ & $\begin{array}{l}\text { Return in one week or when } \\
\text { no complaint }\end{array}$ \\
\hline & $\begin{array}{l}\text { Severe Hypertension } \\
(\geq 160 / 110 \mathrm{mmHg})\end{array}$ & $\begin{array}{c}\text { Oral methyldopa/ } \\
\text { Aldomet } \\
\text { loading dose of } \mathrm{MgSO}_{4}\end{array}$ & Refer to higher level facility \\
\hline Eclampsia & & Loading dose of $\mathrm{MgSO}_{4}$ & $\begin{array}{c}\text { Refer immediately to higher } \\
\text { level facility }\end{array}$ \\
\hline
\end{tabular}

In October 2016, CHEWs in the intervention arm attended a three day, competency-based training workshop. A group of master trainers (MTs) and trainers selected from SMoH and Ob/Gyn and midwifery professionals was established. Pre-and post-training tests assessed immediate changes in knowledge. The training curriculum was based upon WHO as well as the national guidelines for HDP management 24 .

Treatment protocols and a referral decision-making tree for HDPs (also developed based upon WHO recommendations) were provided to $\mathrm{CHEWs}$, to guide identification and treatment for women with HDPs. The protocol and decision-making tree describe ways to identify HDP during ANC (and PNC) and to categorize hypertension as chronic, gestational, or as pre-eclampsia. Furthermore, the guidelines provide information for grading hypertension as mild, moderate, and severe, and management of each category. Training also emphasized how to correctly determine BP, conduct urine protein testing with dipstick, and when to administer anti-hypertensive drugs (alpha methyldopa, Aldomet), as well as counseling clients and referral processes. CHEWs were also instructed how to document the essential elements of their ANC services, for example BP and urine results, past medical history, gestational age, and identifying danger signs and symptoms in pregnancy. Details of counseling and referral, including policy guidelines for referral and the importance of adherence to referral, were emphasized. CHEWs were also oriented on the study procedures, ethical issues, as well as the participant enrollment processes.

CHEWs in the comparison arm did not receive any training on HDP detection and management (other than standard $\mathrm{CHEW}$ services in Nigeria, which includes administering a loading dose of $\mathrm{MgSO}_{4}$ to women with severe $\mathrm{PE} / \mathrm{E}$, and referral).

CHEWs' training on HDP diagnosis, classification, and management was based upon the algorithm shown in Table 1 



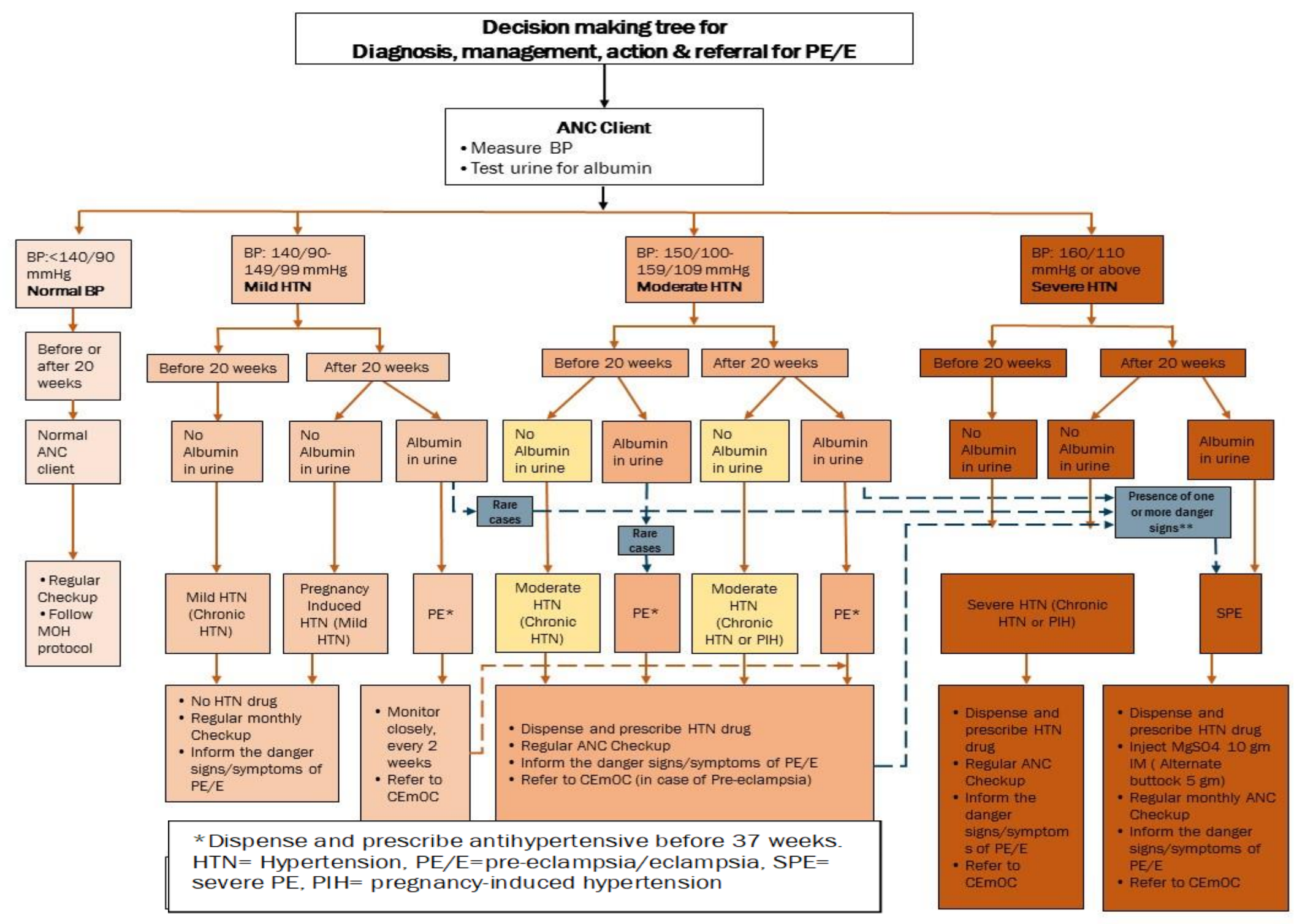

Figure 1: Flow chart for diagnosing and managing hypertension in pregnancy for this study 


\section{CLIENT IDENTIFICATION}

Pregnant women attending an ANC clinic were screened for hypertension and proteinuria. For women with high BP or significant proteinuria, CHEWs documented their socio-demographic characteristics, obtained informed consent, and recruited them into the study. Only hypertensive pregnant women 15 years or older were enrolled. Although the age of consent in Nigeria is 18 years, pregnant women younger than 18 are considered emancipated by virtue of their pregnancy status. And in addition, the national policy for research with adolescents indicates that adolescents can make informed decisions about their medical needs ${ }^{25}$.

CHEWs opened a treatment folder for each client, in which all clinical decisions and medical interventions were documented. Each recruited client was followed until her delivery, and into the immediate postpartum period (up to 48 hours) to determine if she was managed according to the guidelines. Permission for a follow up call was obtained during the informed consent process.

\section{CLIENT REFERRAL}

Guided by the decision-making tree (job aid and treatment algorithm, see Figure 1), if a woman's BP was not controlled, she was referred to a physician at a secondary- or higher level facility. When a woman had severe PE/E, she was administered a loading dose of $\mathrm{MgSO}_{4}$, according to the national standard, and referred to a higher level facility for definitive management. CHEWs displayed job aids in their consultation, treatment, and labor rooms for ease of reference.

To track referrals, CHEWs issued a duplicate copy of a client's completed case notes for the client to take to the referral facility; then, if a client did not present at a referral facility, the CHEW called the client or her family directly. In the comparison arm, CHEWs were encouraged to refer clients with severe cases to higher level facilities for definitive management, but they did not receive training on how to identify and manage HDPs.

\section{SUPPLY OF ANTI-HYPERTENSIVE DRUGS (ALPHA METHYLDOPA)}

Before commencing the study, consultative meetings with Ebonyi SMoH requested their procurement, supply, and monitoring of uptake of anti-hypertensive drugs (alpha methyldopa only) among the study's intervention facilities, staff, and clients. Initial doses of alpha methyldopa were prescribed by CHEWs and obtained from facilities' pharmacies. If stock outs occurred during the study, clients were asked to obtain the drug at a local pharmacy (while efforts were being made to replenish facility supplies). Women were instructed to return for prescription refills at the health facility; BP was re-checked at every visit.

\section{CHEW SUPPORTIVE SUPERVISION AND JOB AIDS}

Chews were monitored and mentored monthly, and clients' records were reviewed during each monitoring visit to ensure chew compliance with ethical and clinical standards. This monthly supportive supervision was in collaboration with Ebonyi $\mathrm{SMoH}$. A SMoH physician provided M\&E and supervision for the management of any adverse events of drugs. During supportive supervision visits, chews were observed for how they measured and determined BP and tested for urine proteins. In instances with no incidences of hypertension at a facility, chews were encouraged to explain the HDP treatment protocol and algorithm (Figure 1). 


\section{SAMPLING, DATA COLLECTION AND ANALYSIS}

The study's design was quasi-experimental and a non-equivalent comparison, in which $40 \mathrm{PHC}$ facilities from 10 LGAs were divided into two arms (5 LGAs in each arm)-experimental and comparison. Four PHC facilities were selected within each, LGA for a total of 20 facilities per study arm. There were three periods of data collection during implementation-at baseline in October 2016, immediate post-training in November 2016, and endline in November 2017.

At baseline, a cross-sectional survey of health care providers' (mainly CHEWs) knowledge and practices was conducted in both study arms using a pre-tested, interviewer-administered questionnaire (October 2016). At the same time, a facility inventory determined availability of commodities and supplies for HDP detection and management. Quarterly facility inventory reviews were conducted throughout the intervention period in the intervention arm.

After CHEWs in the intervention arm were trained on HDP detection and management in November 2016, a post-training test determined any change in their knowledge of HDPs.

At endline, in November 2017, a provider survey of the trained CHEWs arm assessed their knowledge retention. All case notes from enrolled clients were retrieved and reviewed to determine how clients were identified, classified, and managed, in addition to the quality of care provided by CHEWs.

Lastly, in November 2017 in-depth interviews (IDIs) with women diagnosed with HDPs helped to understand their experiences and perceptions of their care from CHEWs, including their perceptions of their pregnancy outcomes. Table 2 charts the data collected at baseline and endline.

Table 2: Data collection activities and number of participants

\begin{tabular}{|c|c|c|c|c|c|c|}
\hline & \multicolumn{3}{|c|}{ Intervention } & \multicolumn{3}{|c|}{ Comparison } \\
\hline & Baseline & $\begin{array}{c}\text { Post- } \\
\text { Training }\end{array}$ & Endline & Baseline & $\begin{array}{c}\text { Post- } \\
\text { Training }\end{array}$ & Endline \\
\hline CHEW interviews & 43 & 36 & $36 *$ & 29 & 0 & $37^{+}$ \\
\hline Clients enrolled with HDP & & & 40 & & & 14 \\
\hline $\begin{array}{l}\text { IDls with women with HDPs } \\
\text { (subset of enrolled clients) }\end{array}$ & & & 25 & & & 9 \\
\hline Facility Inventory & 20 & & 20 & 20 & & 20 \\
\hline
\end{tabular}

*7 CHEWs were not available at endline: ${ }^{+} 8$ additional CHEWs in the comparison arm

\section{DATA MANAGEMENT AND ANALYSIS}

All completed questionnaires were transferred immediately to the Council's Abuja office for data entry and analysis. All hard copies of questionnaires, consent forms, and client case notes were sealed and stored in secured, locked drawers at the Council office. They will be stored for five years before being destroyed.

Data were analyzed with STATA, presented in frequency tables. To answer "Are lower level service providers able to identify, classify, and manage hypertensive disorders in pregnant women and manage appropriately with alpha methyldopa?", a chi-square/Fisher's exact test determined associations among categorical variables. A non-linear difference in difference analysis determined the intervention's effects while accounting for baseline differences. P-values $<0.05$ are considered statistically significant.

Outcomes such as how well HDP was controlled, CVA incidence, and maternal and fetal survival were assessed. Analysis considered whether CHEWs correctly diagnosed and categorized HDPs, as well as women's gestation at initial ANC, diagnosis, and study enrolment. Women diagnosed with moderate hypertension and severe PE/E were interviewed to ascertain whether they received anti-hypertensive drugs 
and $\mathrm{MgSO}_{4}$, as appropriate. Women referred to higher facilities for definitive management were reported upon, and women's gestation at delivery, fetal and maternal outcomes were determined.

To evaluate clients' quality of care, tests of association were conducted, looking closely at client case notes. Qualitative data from IDIs with women who experienced PE/E were digitally recorded, transcribed, translated, and analyzed to understand women's perspectives about their quality of care from CHEWs at PHCs as well as at referral facilities.

\section{ETHICAL REVIEW AND CONSENT}

Ethical approval of this study's protocol was obtained from the Population Council's Institutional Review Board (IRB Protocol 760) in New York, in addition to the National Health Research Ethics Committee (NHREC) at the Federal Ministry of Health $(\mathrm{FMoH})$ in Nigeria as well as the Ebonyi State Research Ethics Committee (MOH/ET/POP/0022/16). All participants (CHEWS and enrolled women) provided their own informed consent for enrollment and subsequent interviews. Administrative and collaborative approval was obtained from Ebonyi's SMoH and LGA local health authorities.

Enrolled women's information was documented by CHEWs, including telephone number and community name, for ease of follow up. A doctor of medicine from $\mathrm{SMoH}$ provided quality control and followed up on any adverse and serious adverse events during the study. 


\section{RESULTS}

The key findings from this intervention include the experiences and perspectives of clients enrolled in the study. Table 3 describes basic the characteristics of participating CHEWs at both the intervention and control PHCs, at baseline and endline. There were no significant socio-demographic differences between the two arms, but their differences in work experience neared significance $(P=0.05)$.

Table 3: CHEWs baseline and endline demographic characteristics

\begin{tabular}{|c|c|c|c|c|c|c|c|}
\hline \multirow[b]{2}{*}{ Characteristic } & \multicolumn{2}{|c|}{ Intervention $(n=79)$} & \multicolumn{2}{|c|}{ Comparison $(n=66)$} & \multicolumn{2}{|c|}{ Total $(n=145)$} & \multirow[b]{2}{*}{ P-value ${ }^{\dagger}$} \\
\hline & $\begin{array}{c}\text { Baseline } \\
(n=43)\end{array}$ & $\begin{array}{c}\text { Endline } \\
(n=36)\end{array}$ & $\begin{array}{c}\text { Baseline } \\
(n=29)\end{array}$ & $\begin{array}{c}\text { Endline } \\
(n=37)\end{array}$ & $\begin{array}{c}\text { Baseline } \\
(n=72)\end{array}$ & $\begin{array}{c}\text { Endline } \\
(n=73)\end{array}$ & \\
\hline \multicolumn{8}{|l|}{ Gender, \%* } \\
\hline Female & 88.4 & 88.9 & 93.1 & 97.3 & 90.3 & 93.2 & \multirow{2}{*}{$0.2 *$} \\
\hline Male & 11.6 & 11.1 & 6.9 & 2.7 & 9.7 & 6.8 & \\
\hline \multicolumn{8}{|l|}{ Age (years), \% } \\
\hline $15-25$ & 11.6 & 8.3 & 3.4 & 8.1 & 8.3 & 8.2 & \multirow{4}{*}{0.4} \\
\hline$>25-35$ & 20.9 & 13.9 & 34.5 & 24.3 & 26.4 & 19.2 & \\
\hline$>35-45$ & 44.2 & 50.0 & 31.0 & 45.9 & 38.9 & 47.9 & \\
\hline$>45$ & 23.3 & 27.8 & 31.0 & 21.6 & 26.4 & 24.7 & \\
\hline \multicolumn{8}{|c|}{ Work experience (years), \% ${ }^{\neq}$} \\
\hline$<1$ year & 23.3 & 2.8 & 6.9 & 45.9 & 16.7 & 24.7 & \multirow{3}{*}{0.05} \\
\hline 1- 3 years & 34.9 & 50.0 & 41.4 & 16.2 & 37.5 & 32.9 & \\
\hline$>3$ years & 41.9 & 47.2 & 51.7 & 37.8 & 45.8 & 42.5 & \\
\hline \multicolumn{8}{|c|}{ RMNCH training in the last 3 years, \% } \\
\hline Yes & 67.4 & 100.0 & 75.9 & 91.9 & 70.8 & 95.9 & 0.8 \\
\hline \multicolumn{8}{|c|}{ Residence at facility, \% } \\
\hline Yes & 48.8 & 33.3 & 34.5 & 32.4 & 43.1 & 32.9 & 0.3 \\
\hline
\end{tabular}

Table 4: Intervention effects on CHEW HDP management, intervention and comparison arms

\begin{tabular}{|c|c|c|c|c|c|c|c|c|}
\hline \multirow[t]{2}{*}{ CHEWs' Management of HDPs } & \multicolumn{2}{|c|}{$\begin{array}{c}\text { Intervention } \\
(n=79)\end{array}$} & \multicolumn{2}{|c|}{$\begin{array}{c}\text { Comparison } \\
(n=66)\end{array}$} & \multicolumn{2}{|c|}{$\begin{array}{c}\text { Total } \\
(n=45)\end{array}$} & \multirow{2}{*}{$\begin{array}{c}\text { P- } \\
\text { Value }\end{array}$} & \multirow{2}{*}{ 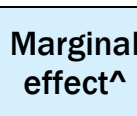 } \\
\hline & $n$ & $\%^{\dagger}$ & $n$ & $\%^{\dagger}$ & $\mathrm{n}$ & $\%^{\dagger}$ & & \\
\hline Correct description of BP measurement & 46 & 58.2 & 21 & 31.8 & 67 & 46.2 & $<0.001$ & 0.78 \\
\hline CHEWs correctly defining HDP & 50 & 63.3 & 34 & 51.5 & 84 & 57.9 & 0.02 & 0.36 \\
\hline CHEWs correctly grading hypertension & 26 & 32.9 & 3 & 4.5 & 29 & 20.0 & 0.03 & 0.60 \\
\hline $\begin{array}{l}\% \text { of providers who properly described } \\
\text { how to manage BP }\end{array}$ & 44 & 55.8 & 17 & 25.8 & 61 & 42.1 & 0.001 & 0.57 \\
\hline $\begin{array}{l}\text { Knowledge of when to introduce } \\
\text { anti-hypertensive drugs }\end{array}$ & 37 & 46.8 & 8 & 12.1 & 45 & 31.0 & $<0.001$ & 0.38 \\
\hline $\begin{array}{l}\text { Knowledge of when to stop } \\
\text { anti-hypertensive drugs }\end{array}$ & 31 & 39.2 & 4 & 6.1 & 35 & 24.1 & 0.03 & 0.52 \\
\hline $\begin{array}{l}\text { Knowledge of when to rapidly lower } \\
\text { stroke risk in pre-eclampsic women }\end{array}$ & 34 & 43.0 & 17 & 25.8 & 51 & 35.2 & 0.008 & 0.49 \\
\hline $\begin{array}{l}\text { Knowledge of when to administer } \\
\mathrm{MgSO}_{4} \text { to pre-eclampsic women }\end{array}$ & 40 & 50.6 & 21 & 31.8 & 61 & 42.1 & 0.02 & 0.41 \\
\hline
\end{tabular}

${ }_{\dagger} \mathrm{n} / \mathrm{N} * 100$. $\neq \mathrm{P}$-value of the difference-in-differences estimate accounting for baseline differences in intervention and comparison arms; $\mathrm{P}<0.05$ considered statistically significant; ${ }^{\wedge}$ Average effect of training on CHEW HDP management in the intervention vs. comparison arm ${ }^{1}$

1 i.e. A 0.78 marginal effect illustrates, on average, intervention CHEWs as 78 percentage points more likely to correctly describe BP measurement 
Table 4 on the preceding page shows that the training's implementation was followed by a change in CHEWs' knowledge and ability to manage HDPs.

Table 5 shows that CHEWs in the intervention arm had improved knowledge and abilities to distinguish $\mathrm{PE} / \mathrm{E}$ from other forms of hypertension than those in the comparison arm.

Table 5: CHEWs ability to distinguish between forms of hypertensive disorders in pregnancy across intervention and comparison arms

\begin{tabular}{|c|c|c|c|c|c|c|c|c|}
\hline \multirow[t]{2}{*}{ Type of Hypertension } & \multicolumn{2}{|c|}{$\begin{array}{c}\text { Intervention } \\
(n=79)\end{array}$} & \multicolumn{2}{|c|}{$\begin{array}{c}\text { Comparison } \\
(n=66)\end{array}$} & \multicolumn{2}{|c|}{$\begin{array}{c}\text { Total } \\
(n=145)\end{array}$} & \multirow[t]{2}{*}{ P-Values $\ddagger$} & \multirow{2}{*}{ 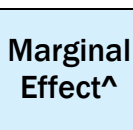 } \\
\hline & $n$ & $\%^{\dagger}$ & $n$ & $\%^{\dagger}$ & $n$ & $\%^{\dagger}$ & & \\
\hline Chronic & 34 & 43.0 & 16 & 24.2 & 50 & 34.5 & 0.1 & 0.35 \\
\hline Gestational & 36 & 45.6 & 20 & 30.3 & 56 & 38.6 & 0.6 & 0.18 \\
\hline Pre-eclampsia & 51 & 64.6 & 32 & 48.5 & 83 & 57.2 & $<0.001$ & 0.59 \\
\hline Severe pre-eclampsia & 32 & 40.5 & 18 & 27.3 & 50 & 34.5 & -* & _* \\
\hline Eclampsia & 55 & 69.6 & 44 & 66.7 & 99 & 68.3 & 0.01 & 0.41 \\
\hline
\end{tabular}

${ }^{*} 72$ observations not reported for this variable, hence no meaningful analysis; ${ }^{\dagger} \mathrm{n} / \mathrm{N}^{\star} 100{ }^{\wedge}{ }^{\wedge}$ The average effect of the training on $\mathrm{CHEWs}$ ability to distinguish types of HYPERTENSION in the intervention arm over the comparison arm; ₹ P-value of the difference-in-differences estimate; accounting for baseline differences in the intervention and comparison arms; $P<0.05$ is considered statistically significant; Significant results in bold

In both the intervention and comparison arms, CHEWs mostly identified alpha methyldopa and Nifedipine as the drug of choice for controlling BP (Table 6). In addition, alpha methyldopa was the most prescribed anti-hypertensive drug in both arms, however, prescription of this drug did not differ between the intervention and control arms. At endline, almost no CHEW in either arm prescribed hydralazine, despite intervention CHEWs' awareness of it as a drug used to control BP.

Table 6: Prescribing practices among CHEWs in intervention and comparison arms ${ }^{2}$

\begin{tabular}{|c|c|c|c|c|c|c|c|}
\hline & \multicolumn{2}{|c|}{$\begin{array}{c}\text { Intervention } \\
\quad(n=79)\end{array}$} & \multicolumn{2}{|c|}{$\begin{array}{c}\text { Comparison } \\
(n=66)\end{array}$} & \multicolumn{2}{|c|}{$\begin{array}{c}\text { Total } \\
(n=145)\end{array}$} & \multirow[t]{2}{*}{ P-value ${ }^{a}$} \\
\hline & $n$ & $\%^{\ddagger}$ & $n$ & $\%^{\ddagger}$ & $n$ & $\%^{\ddagger}$ & \\
\hline \multicolumn{8}{|l|}{ What specific drugs are used to control BP? ${ }^{\dagger}$} \\
\hline Labetalol & 7 & 8.9 & 5 & 7.6 & 12 & 8.3 & 0.7 \\
\hline alpha methyldopa/Aldomet & 39 & 49.4 & 20 & 30.3 & 59 & 40.7 & 0.02 \\
\hline Nifedipine & 37 & 46.8 & 26 & 39.4 & 63 & 43.4 & 0.4 \\
\hline Hydralazine & 9 & 11.4 & 9 & 13.6 & 18 & 12.4 & 0.7 \\
\hline Aware/ever heard of alpha methyldopa? & 54 & 68.4 & 39 & 59.1 & 93 & 64.1 & 0.2 \\
\hline Prescribe anti-hypertensive in facility & 47 & 59.5 & 33 & 50.0 & 80 & 55.2 & 0.25 \\
\hline \multicolumn{8}{|l|}{ Most commonly prescribed anti-hypertensive ${ }^{*}$} \\
\hline Labetalol & 13 & 27.7 & 1 & 3.0 & 14 & 17.5 & 0.006 * \\
\hline alpha methyldopa/Aldomet & 23 & 48.9 & 14 & 42.4 & 37 & 46.3 & 0.6 \\
\hline Nifedipine & 7 & 14.9 & 10 & 30.3 & 17 & 21.3 & 0.1 \\
\hline Hydralazine & 2 & 4.3 & 3 & 9.1 & 5 & 6.3 & $0.6 *$ \\
\hline
\end{tabular}

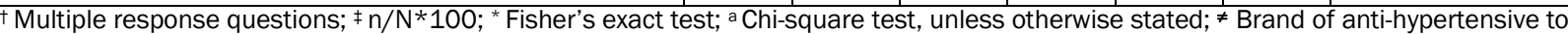
be prescribed could be influenced by other facility level factors and not necessarily the intervention; Significant results in bold

2 Due to the multiple response questions and the low number of responses in this section, a difference in difference analysis accounting for baseline differences in the intervention and comparison arms was not feasible. We recognize this as a limitation. 


\section{MANAGEMENT OF WOMEN WITH HYPERTENSION IN PREGNANCY}

There were no significant differences between the two study arms in gestational age at booking or gestational age at diagnosis. We found a difference in gestational age at delivery between the two study arms $(P=0.02)$, but this difference may be due to the fewer women in the comparison arm $(n=14)$.

Table 7: Women's backgrounds, at enrolment, in intervention and comparison arms

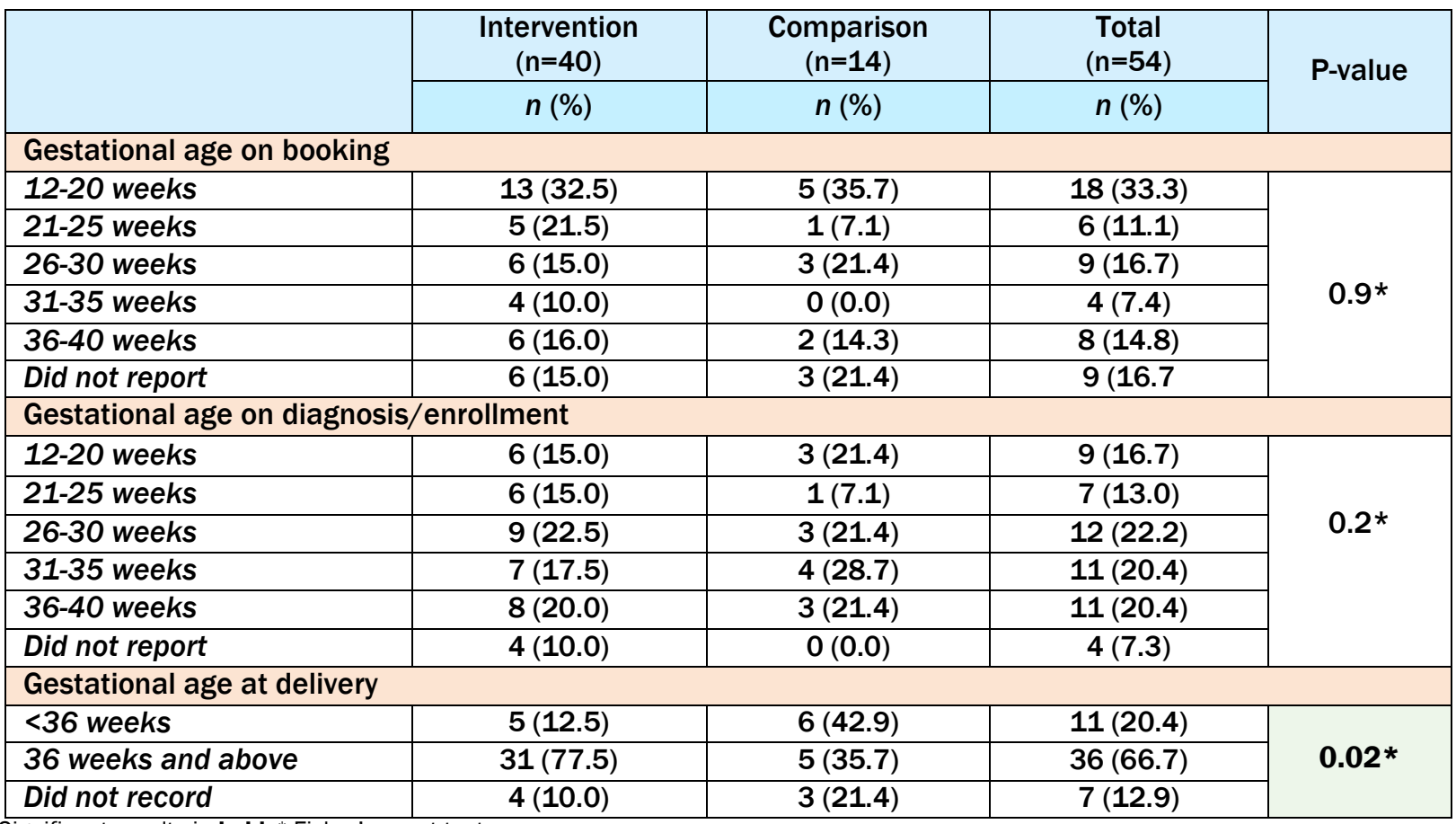

Significant results in bold; * Fisher's exact test

Following CHEWs' training, only one client seen at an intervention PHC center was mis-classified for HDP and its severity. By contrast, CHEWs in the comparison arm misclassified nine women (see Table 8, following page).

Among women with moderate to severe hypertension requiring anti-hypertensive drugs upon diagnosis, more women in the intervention arm received treatment $(p<0.001)$. Furthermore, 50 percent of women with severe pre-eclampsia in the intervention arm received a loading dose of $\mathrm{MgSO}_{4}$ upon diagnosis, while no woman in the comparison arm received a $\mathrm{MgSO}_{4}$ loading dose (Table 8).

During this study's duration, a total of five maternal deaths occurred-one in the intervention arm (intrapartum death) and four in the comparison arm (one antepartum, 2 intrapartum, one postpartum). The woman who died in the intervention arm did not receive a loading dose of $\mathrm{MgSO}_{4}$ after her diagnosis of severe pre-eclampsia; all women who received a loading dose survived. A total of 13 fetal deaths also occurred: four in the intervention arm ( 3 stillbirths, one early neonatal death) and nine in the comparison arm (all stillbirths). No mothers of the infants who died received a loading dose of $\mathrm{MgSO}_{4}$.

These maternal and perinatal deaths were due to a combination of $\mathrm{MgSO}_{4}$ unavailability at facilities, at the time of diagnosis of severe $\mathrm{PE} / \mathrm{E}$, and client failures to complete the referral process-and not receive the drug. Upon study recruitment (immediately after diagnosis), only four women were given anti-hypertensive drugs in the comparison arm, yet 29 in the intervention arm were. Similarly, of the women diagnosed with severe $\mathrm{PE} / \mathrm{E}$ at recruitment, only nine women were given $\mathrm{MgSO}_{4}$ (2 in the comparison arm and 7 in the intervention arm). 
Table 8: Pregnancy outcomes among women with HDPs recruited, intervention and comparison

\begin{tabular}{|c|c|c|c|c|}
\hline \multirow{2}{*}{$\begin{array}{l}\text { Pregnancy outcomes among women enrolled } \\
\text { with hypertension in study sites }\end{array}$} & $\begin{array}{c}\text { Intervention } \\
(\mathrm{n}=40)\end{array}$ & $\begin{array}{c}\text { Comparison } \\
(n=14)\end{array}$ & $\begin{array}{c}\text { Total } \\
(n=54)\end{array}$ & \multirow[t]{2}{*}{ P-value } \\
\hline & $n(\%)$ & $n(\%)$ & $n(\%)$ & \\
\hline \multicolumn{5}{|l|}{ Diagnosis at enrollment } \\
\hline Correctly Diagnosed Pre-Eclampsia & $1(2.5)$ & $1(7.1)$ & $2(3.7)$ & \multirow{5}{*}{$<0.001 *$} \\
\hline Correctly diagnosed Severe PE & $15(37.5)$ & $0(0.0)$ & $15(27.8)$ & \\
\hline Correctly diagnosed Gestational Hypertension & $21(52.5)$ & 1(7.1) & $22(40.7)$ & \\
\hline Correctly diagnosed Chronic Hypertension & $2(5.0)$ & 3(21.4) & $5(9.3)$ & \\
\hline Mis-classified & $1(2.5)$ & $9(64.4)$ & $10(18.5)$ & \\
\hline \multicolumn{5}{|c|}{ Correct HDP classification at enrollment: mild, moderate, severe/chronic, gestational/PE, severe PE/E } \\
\hline Yes & $37(92.5)$ & $1(7.1)$ & $38(70.4)$ & \multirow{2}{*}{$<0.001 *$} \\
\hline No & $3(7.5)$ & $13(92.9)$ & $16(29.6)$ & \\
\hline \multicolumn{5}{|c|}{ Received anti-hypertensive on diagnosis at recruitment for moderate to severe hypertension, severe $\mathrm{PE} / \mathrm{E}$} \\
\hline Yes & $29(72.5)$ & $4(28.6)$ & $33(61.1$ & \multirow{2}{*}{$0.002 *$} \\
\hline No & $10(71.1)$ & $11(27.5)$ & $21(38.9)$ & \\
\hline \multicolumn{5}{|l|}{ Received $\mathrm{MgSO}_{4}$ on diagnosis at enrollment } \\
\hline Yes & $7(17.5)$ & $2(14.3)$ & $9(16.7)$ & \multirow{2}{*}{$0.9 *$} \\
\hline No & $33(82.5)$ & $12(85.7)$ & $45(83.3)$ & \\
\hline \multicolumn{5}{|c|}{ Anti-hypertensive at first follow up after diagnosis of moderate to severe hypertension, severe PE/E } \\
\hline Yes & $21(60.0)$ & $2(18.2)$ & $23(50.0)$ & \multirow{2}{*}{$0.02 *$} \\
\hline No & $14(40.0)$ & $9(81.8)$ & $23(50.0)$ & \\
\hline \multicolumn{5}{|l|}{ Received $\mathrm{MgSO}_{4}$ on diagnosis at enrollment } \\
\hline Yes & $5(14.3)$ & $2(18.2)$ & $7(15.2)$ & \multirow{2}{*}{$0.8^{*}$} \\
\hline No & $30(85.7)$ & $9(81.8)$ & $39(84.8$ & \\
\hline Number of pregnant women referred & $8(20.0)$ & $2(14.3)$ & $10(18.5)$ & 0.7 \\
\hline \multicolumn{5}{|l|}{ Fetal outcome } \\
\hline Alive & $36(90.0)$ & $5(35.7)$ & $41(75.9)$ & \multirow{3}{*}{$<0.001 *$} \\
\hline Dead & $4(10.0)$ & $9(64.3)$ & $13(24.1)$ & \\
\hline Total & $40(100.0)$ & $14(100.0)$ & $54(100.0)$ & \\
\hline \multicolumn{5}{|l|}{ Maternal outcome } \\
\hline Alive & $39(97.5)$ & $10(71.4)$ & $49(90.7)$ & \multirow{3}{*}{$0.004 *$} \\
\hline Dead & $1(2.5)$ & $4(28.6)$ & $5(9.3)$ & \\
\hline Total & 40(100.0) & $14(100.0)$ & $54(100.0)$ & \\
\hline
\end{tabular}

More children survived with early administration of anti-hypertensive drugs to women with moderate to severe hypertension, and a loading dose of $\mathrm{MgSO}_{4}$ to women with severe pre-eclampsia $(\mathrm{p}<0.005)$. No women who received $\mathrm{MgSO}_{4}$ died in the intervention arm.

Table 9. Effects of $\mathrm{MgSO}_{4}$ and anti-hypertensive on fetal and maternal survival

\begin{tabular}{|c|c|c|c|c|}
\hline & Intervention & Comparison & Total & p-value \\
\hline \multicolumn{5}{|c|}{ Diagnosed severe $\mathrm{PE} / \mathrm{E}$, received $\mathrm{MgSO}_{4}$ at enrollment-Fetal Survival } \\
\hline Alive & $6(85.7)$ & $0(0.0)$ & $6(66.7)$ & \multirow{3}{*}{$<0.001 *$} \\
\hline Dead & $1(14.3)$ & $2(100.0)$ & 3 (33.3) & \\
\hline Total & $7(77.8)$ & $2(22.2)$ & $9(100.0)$ & \\
\hline \multicolumn{5}{|c|}{ Diagnosed moderate to severe hypertension, received anti-hypertensive at enrollment-Fetal Survival } \\
\hline Alive & $20(83.3)$ & $1(50)$ & $21(80.8)$ & \multirow{3}{*}{$0.003^{*}$} \\
\hline Dead & $4(16.7)$ & $1(50)$ & $5(19.2)$ & \\
\hline Total & 24 (92.3) & $2(7.7)$ & $26(100)$ & \\
\hline \multicolumn{5}{|c|}{ Diagnosed moderate to severe hypertension, received anti-hypertensive at enrollment-Maternal Survival } \\
\hline Alive & $24(100)$ & 2(100) & 26(100.0) & \multirow{3}{*}{ 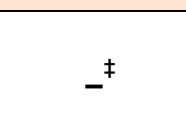 } \\
\hline Dead & $0(0.0)$ & $0(0.0)$ & $0(0.0)$ & \\
\hline Total & 24(92.3) & 2(7.7) & $26(100.0)$ & \\
\hline
\end{tabular}




\section{FACILITY STOCK REVIEWS}

A pre-post assessment of the 20 facilities from the comparison and intervention arms determined monthly availability of commodities for effective HDP management (figures 2 and 3) over the implementation period (December 2016 to November 2017). When Ending Eclampsia activities started in June 2016, stocks of key supplies was generally poor (Figure 2). Most Ending Eclampsia facilities had no anti-hypertensive drugs, calcium gluconate, urine test strips, etc. The project encouraged-and had impact upon-the stocking of such commodities (Figure 2).

An industrial action (or workers' strike) in June 2017 lasting about two weeks, an effort of the Joint Health Sector Union (JOHESU-minus doctors) in Nigeria, lead to reduced supply availability. JOHESU is the largest umbrella of the health workforce, therefore any attempt of industrial action can result in total facility closures, leading to an inability for $\mathrm{SMoH}$ or Central Medical Stores to supply commodities. Consequently, when the team visited to collect data during that period, not all facilities had resumed operation, despite the resolution of the union to resume work.

Importantly, this period (June and July 2017) was characterized by extensive and massive health provider transfers due to the introduction of PHCUOR (Primary Health Care Under One Roof policy) in Ebonyi, causing another reduction in equipment and commodity availability. Some BP machines were not the property of facilities but "privately owned," and left when staff were transferred. In addition, from June until November 2017, some facilities reported damaged BP machines, which contributed to the reduced availability of functional BP machines.

While all facilities had functional BP machines at baseline, there was a decline in their availability at endline. Although stocks of urine test strips, calcium gluconate, $\mathrm{MgSO}_{4}$, and anti-hypertensive drugs increased, the trend indicates not all facilities consistently stocked these commodities and supplies. $\mathrm{MgSO}_{4}$ appeared to expire more frequently at facilities in the comparison arm, especially at baseline.

Figure 2. Availability of commodities and supplies for detecting HDPs in comparison facilities, June 2016 - November 2017

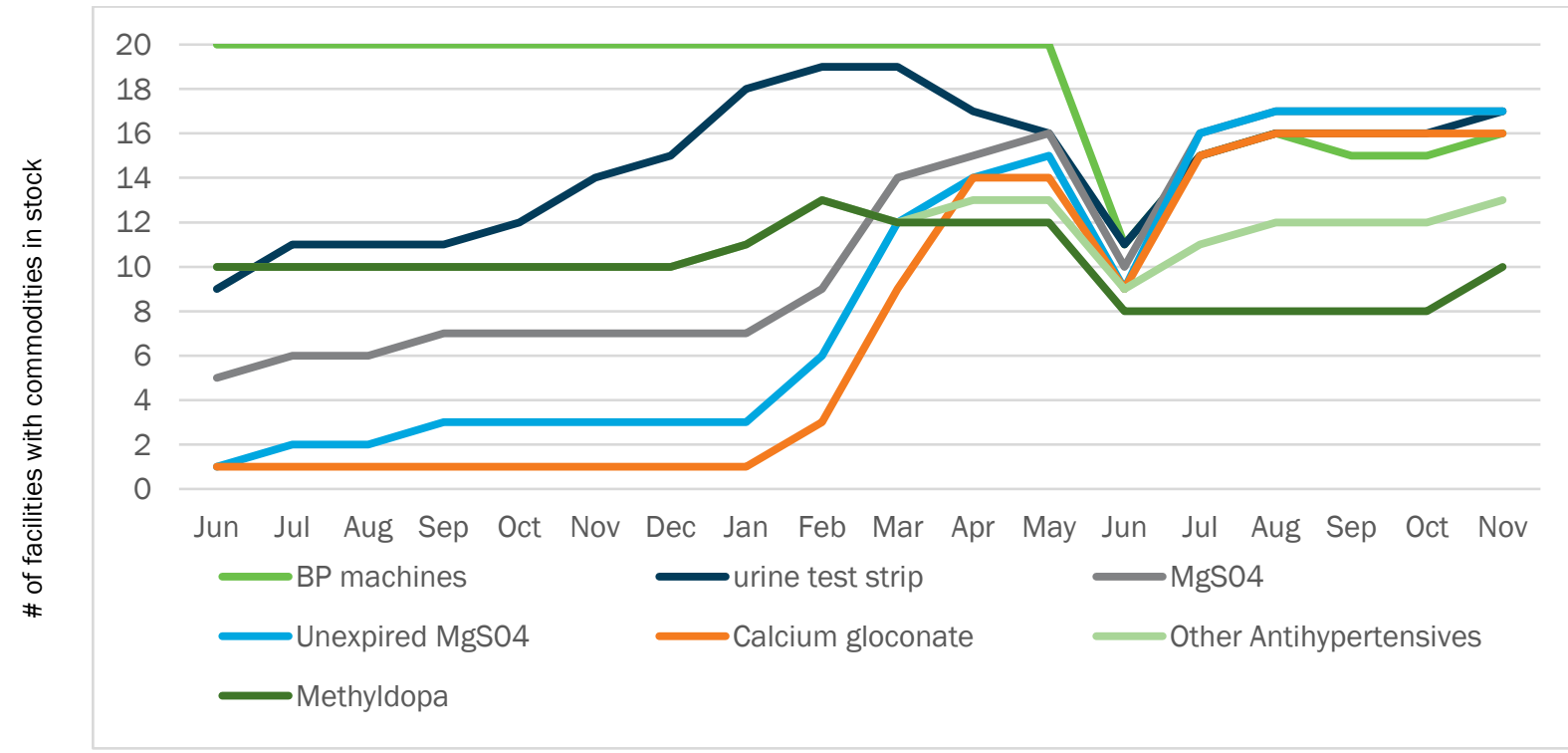

Note: Facility assessment conducted in $20 \mathrm{PHCs}$ 
Figure 3. Availability of commodities and supplies for detecting HDPs in intervention facilities June 2016 - November 2017

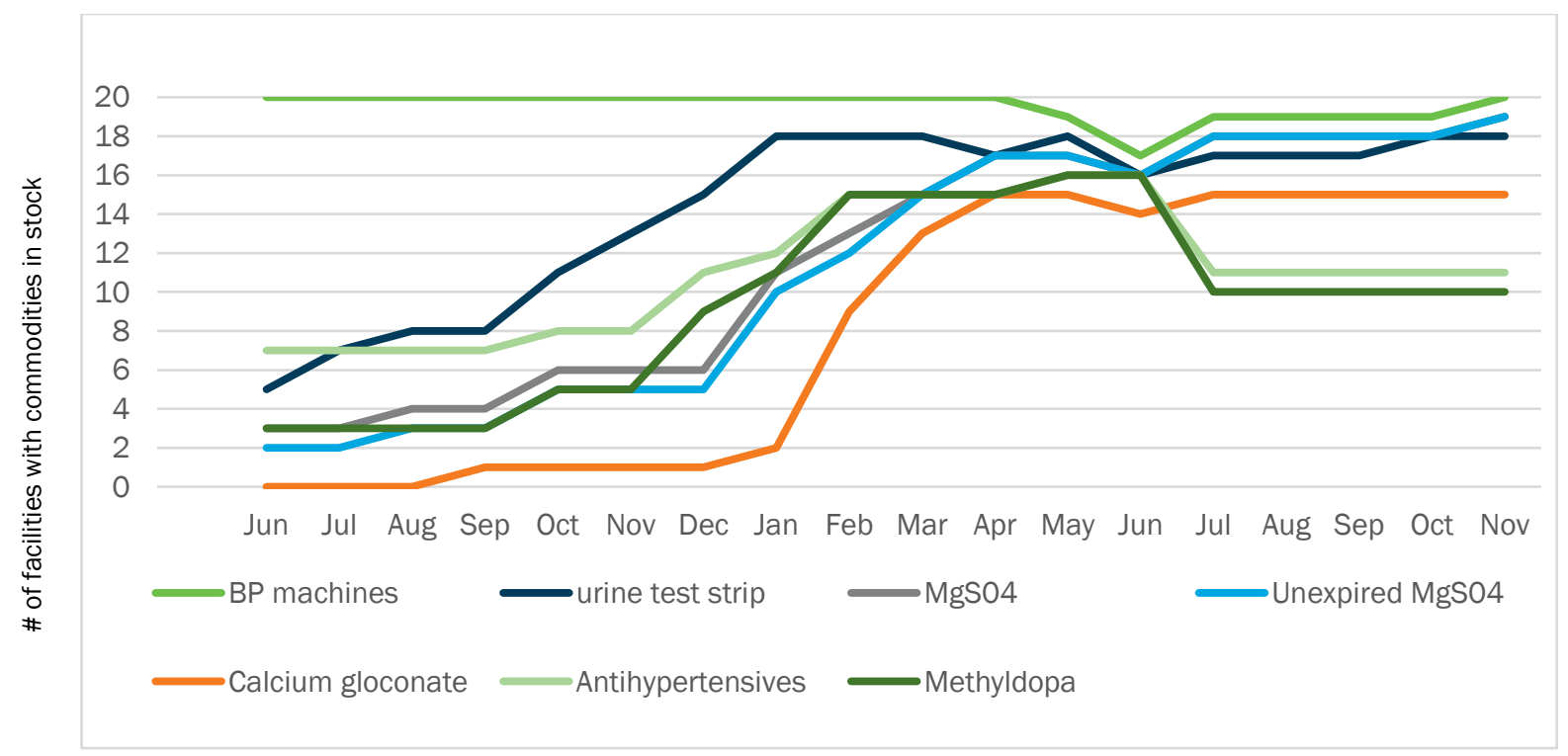

Note: Facility assessment conducted in 20 PHCs

\section{CLIENT ATTENDANCE AND SERVICES}

More women attended facilities for ANC in the intervention arm (figures 4 and 5). Not every woman received BP measurement or urine tests at each visit, although national standards stipulate that every woman should be screened at every visit. Following the intervention, more women had BP and urine checked during ANC visits than pre-intervention, and this consistently increased overtime: At first ANC visit, 94 percent of women had BP measured, while 85 percent had a urine test.

Figure 4 shows that total BP measurement was slightly higher than total urine tested. Average monthly BP measurement was 177 (standard deviation 57.5) and average monthly urine testing was 137 (standard deviation 71.8).

Figure 4. Frequency of ANC visit and HDP screening at comparison facilities June 2016 - November 2017

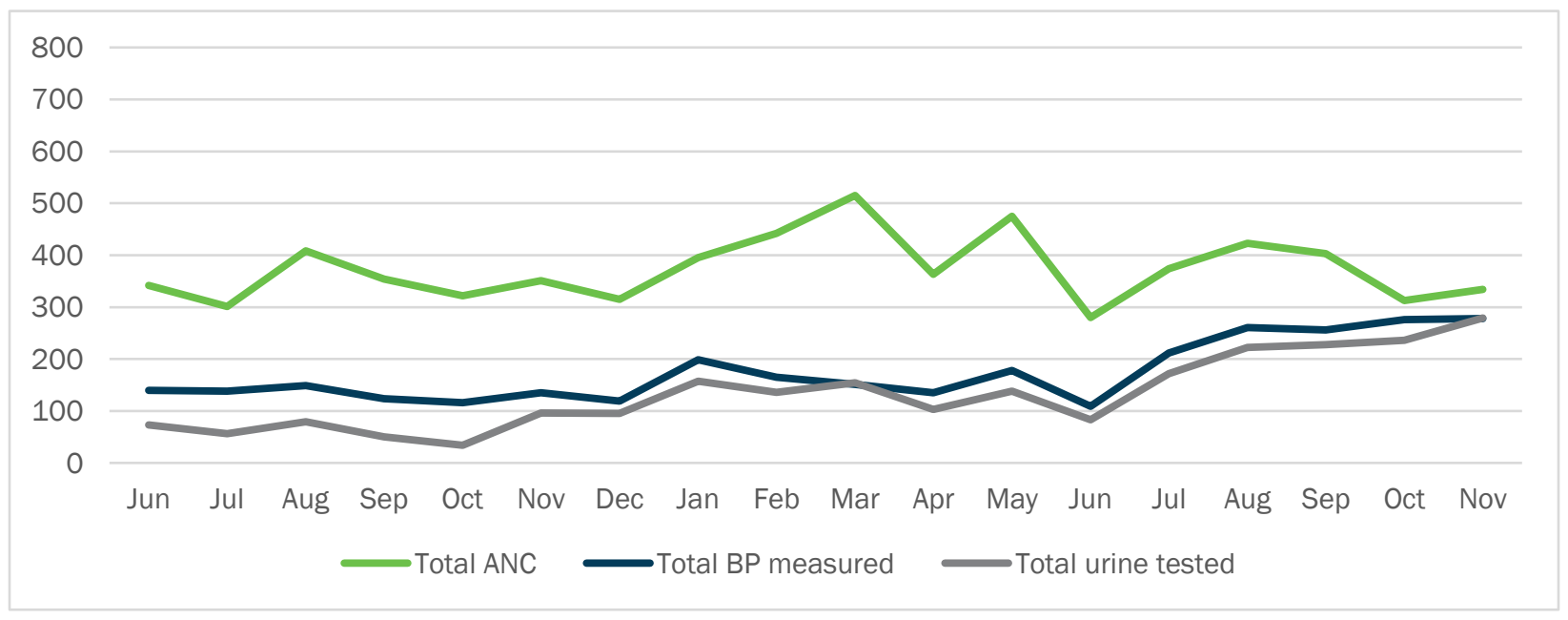


Figure 5 illustrates greater total BP measurement than total urine tests. Average monthly BP measurement was 433 (standard deviation 93.8) while average monthly urine testing was 307 (standard deviation 126.3).

Figure 5. Frequency of ANC visit and HDP screening at intervention facilities June 2016 - November 2017

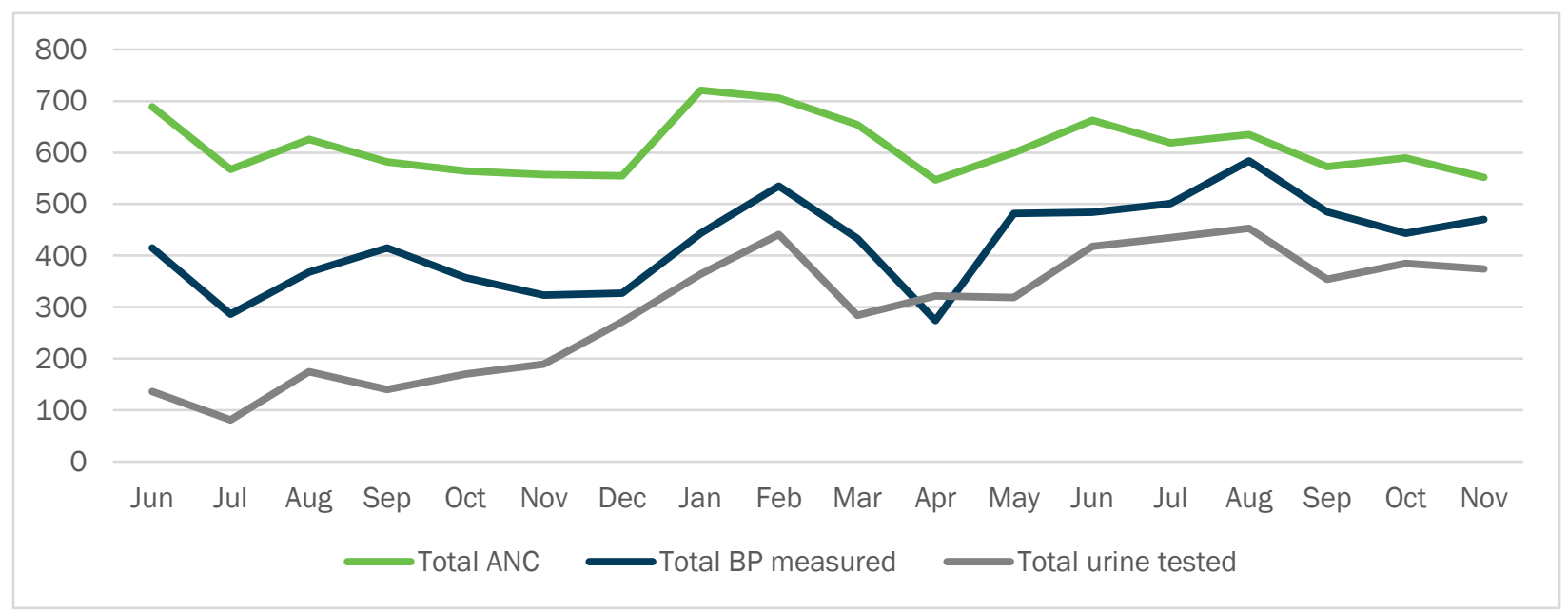

\section{WOMEN'S EXPERIENCES}

This section draws upon qualitative interviews after the intervention with women who experienced PE/E, in both the intervention $(n=25)$ and comparison $(n=9)$ sites. Transcripts were reviewed for correctness. The team analyzed the transcripts for emerging themes, which resulted in categorization according to:

1. What women know about hypertension in pregnancy?.

2. Women's perceptions about the content of their care

3. Women's perceptions of provider prescription habits, commodity supplies, and follow up care

4. Women's failure to complete referral processes due to inadequate information from facilities

5. Women's perceptions of CHEWs' care for hypertensive disorders at PHCs, and

6. Late ANC registration and inconsistent ANC impair early detection and management of HDPs.

\section{WHAT DO WOMEN KNOW ABOUT HYPERTENSION IN PREGNANCY?}

Women's understanding and perceptions of HDP varied. Some thought that there are specific symptoms that might provoke them to consider they had high BP. Even when symptoms occur (headaches, dizziness) women tend to ascribe the symptoms to more familiar health conditions such as malaria in pregnancy.

"I felt it was malaria that I was having, and I started taking malaria drugs and after taking it, it did not stop so I went to the health center where I registered for antenatal care, and they checked me and told me that what I am suffering from is not malaria, but it is high blood pressure that I am suffering from."

HPD survivor, 22 years of age, multigravida, intervention arm

Some women could not recognize the onset of their hypertension, while some only realized it after they were told by their health providers. 
"I didn't know I had hypertension. My pregnancy was seven months when I started having headache and fever. It was when I went to the maternity and they checked me and told me that I have hypertension."

HDP survivor, age 21, primigravida, comparison arm

Some women in the intervention arm were aware of negative consequences of HDPs, if not properly managed, associating HDP with complications such as pre-term birth, miscarriage, maternal death, and prolonged maternal morbidity. Women in the intervention arm better understood the need for careful management of any hypertension to prevent complications and death.

"It could have made the baby to go to my heart or I could have delivered the baby when it is not due for delivery or they will do it operation." HDP survivor, age 30, multigravida, intervention arm

"Pregnant woman that is having blood pressure [hypertension], if not properly managed the person's child will die. [Health care workers] will start telling the pregnant woman another story."

HDP survivor, age 32, multigravida, intervention arm

\section{WOMEN'S PERCEPTIONS OF THE CONTENT OF THEIR CARE}

Generally, but especially in intervention communities, women reported high satisfaction and favorable opinions of their providers' attitudes, both for them and their care. Overall, women in the intervention arm reported improved care experiences, and many women seen at intervention facilities believe their care was adequate. In both arms, women felt respected by their care providers, both at PHC and referral facilities.

"[The care provider] was very careful giving me blood pressure drugs when I come. Those health providers used to take good care of me, if I come, they will start calling me with sweet names and they use to play with me, they have good attitude towards me."

HDP survivor, age 35, multigravida, intervention arm

"You know, the health provider that attended to me lives in our community, even though she's not originally from here; but she interacts with us very well, so when we come for antenatal care visits, she treats us kindly to make us happy." HDP survivor, age 23, primigravida, comparison arm

This project used health talks and communication to improve women's knowledge of important pregnancy issues and empowered women to ask questions around their health and on any clinical and laboratory findings. Similarly, women also reported increased communication between them and their care providers. Women received health talks on their necessary health services and actions they should take in cases of abnormal results.

"They used to give us health talks on different topics. What they teach today is not what they will teach tomorrow, and that is the first thing they do before conducting health checks on us."

HDP survivor, age 28, multigravida, comparison arm

"Yes, I used to feel very happy whenever I come for antenatal. After giving us a talk and I ask questions and after answering me, I will be glad and when I am going, I will not be thinking about anything."

HDP survivor, age 30, multigravida, intervention arm

While client responses to health talks and communication were impressive, some clients were unhappy with their care providers' explanations of their clinical and laboratory test results. Some women recalled BP results shared, but were not told about urine test results. In some cases, health care providers had informed women of their test findings, but women could not recall them. Some women in the intervention arm feel that health care providers intentionally do not communicate BP and urine tests results, especially when findings are abnormally high. Providers on occasion do not reveal findings to clients even when symptoms are severe enough to require referral. 
"You know, sometimes these nurses like to hide somethings for their patients. They don't like telling us- like now if my blood pressure is high, they won't tell me my blood pressure is high, they will tell me to go to somewhere else that is higher [higher level facility] than their own facility. That the higher facility will treat me the way I am supposed to be treated. So, it's all these things, sometimes I will ask them what my blood pressure is? They will tell me not to worry, but I should go to somewhere else that is not something they can handle again."

HDP survivor, age 40, multigravida, intervention arm

"They checked my blood pressure, not urine. She did not tell me anything about my result. It was when my husband asked them, 'Why they are still keeping me?' that the provider said my blood pressure was high."

HDP survivor, age 28, primigravida, comparison arm

\section{WOMEN'S PERCEPTIONS OF PROVIDER PRESCRIPTION HABITS, COMMODITY SUPPLIES AND FOLLOW UP CARE}

Women in the intervention arm reported better prescription practices than those in the comparison arm. Some women received appropriate anti-hypertensive drugs but did not know specifics about dosages or frequency, and some felt it was usual for health care providers to not provide prescription specifics. Women also complained that CHEWs sometimes instruct them to purchase their anti-hypertensive drugs from outside sources due to lack of drug availability at facilities:

"I don't know, you know, what they normally do in the hospital, is that they give you drugs without telling you the name of the drugs. If the drugs names were written [prescribed] for me to go and buy it, is then that I will know the names of the drugs. They just gave me [tablets], and I looked at it and took [swallowed] it without knowing the names."

HDP survivor, age 30, multigravida, intervention arm

"After those drugs and injections, they saw it was not working. It was then that they referred me to Federal Medical Center."

HDP survivor, age 30, multigravida, intervention arm

Some women who purchased their own drugs, from private sources, reported paying more than they could afford. These women recommend the government ensure pro-poor, stable, and accessible drug supplies, especially for pregnant women, to mitigate unaffordable health care.

"The medicine was costly. I paid gradually [in installment] when I don't have money, but when I had money I paid in full."

HDP survivor, age 25, multigravida, comparison arm

"What I am telling the government is, for them to know how to improve this drug, so that it can reach both the rich and the poor. They should be giving it to every pregnant mother, because there are some that have finance problem. They should make it affordable for every pregnant woman."

HDP survivor, age 27, multigravida, intervention arm

\section{WOMEN'S FAILURE TO COMPLETE REFERRAL PROCESS—DUE TO INADEQUATE INFORIMATION FROM REFERRING FACILITIES}

Issues with referrals to higher level facilities remain. While health providers made efforts to refer women to for definitive management, some women did not visit referral facilities despite their continuous elevated BP. This poses a challenge to PHC HDP management. Even when women complete their referrals, no referral process provides continuity of care, especially a dual process reporting back to the PHC facility. As a result, women often do not return to their originating PHCs for care after attendance and treatment at referral facilities.

"Yes, I was referred to Federal Medical Center because of the high blood pressure, but I did not go to where I was referred."

HDP survivor, age 25, multigravida, intervention arm 
Women from both study arms failed to complete their referral process due to lack of detail and discussion at their originating PHCs on the reasons for their referrals. These gaps in communication lead to declines and non-adherence within the referral process. Some women complained of lack of financial reserves for transportation to referral centers. CHEWs sometimes do not refer women to facilities closest to them. Women often resort to borrowing to enable travel to referral centers.

"I usually enter okada [motorcycle] from Ogwor to Afikpo, I will say that it is far, as someone who has nothing doing... we are just managing our best, we struggle to eat, he [husband] is trying his best, anytime they said come, he will try to make sure that I go even if it means borrowing, he will do so to ensure that I went."

HDP survivor, age 30, multigravida, intervention arm

Sometimes women refused the recommended means of care. Some women were recommended for hospital admission, but insisted on returning home due to lack of finances. Financial burdens are a significant factor in whether women adhere to prescribed care (including referrals).

"When I got to Afikpo, they found out that I have high blood pressure. They said that they will give me bedrest, I told them to allow me to go and look for money. I came back and spent two days at the hospital."

HDP survivor, age 36, multigravida, intervention arm

\section{WOMEN'S PERCEPTIONS OF CHEWs' CARE FOR HYPERTENSION IN PREGNANCY}

Women in the intervention arm were accepting of CHEWs' care provision. Some women mentioned CHEWs' importance at PHCs, for attending to pregnant women, including HDP care. These women's views reflect CHEWs' perceived respect for women's dignity.

"Had it been that I didn't come to this health center, I didn't know what could have been the condition of me and my baby, because this health center is really trying in to provide services. They take care of pregnant women very well, especially in the area of hypertension."

HDP survivor, age 27, multigravida, intervention arm

\section{LATE ANTENATAL CARE REGISTRATION AND INCONSISTENT CONTACT IMPAIR EARLY DETECTION AND MANAGEMENT OF HYPERTENSION IN PREGNANCY}

Late ANC registration is still common. Generally, pregnant women's first ANC contact is after 20 weeks' gestation-in both study groups. Women also appear to simultaneously register in at least two facilities for ANC. In some cases, women were already having complications by the time of their initial ANC at a facility:

"I know that I did not start antenatal on time. It was when I started feeling somehow [abnormal] that my husband insisted that I should go to the maternity and register. By that time, I was six months pregnant."

HDP survivor, age 30, primigravida, comparison arm

In addition to registering for ANC at multiple facilities, women may also seek care from religious groups or traditional birth attendants, due to pressure from friends and family.

"I went to the tradition medicine when I was pregnant, you know that if you have problem, many people will be suggesting and advising you to go here or there, you will continue to move from one place to another."

HDP survivor, age 38, multigravida, comparison arm

"Let me tell you, I came here [PHC center] to confirm my pregnancy, and that was at 18 weeks, but I'm used to receiving treatment at Mama Mgbo [a traditional birth attendant]."

HDP survivor, age 38, multigravida, comparison arm 


\section{DISCUSSION}

Given HDPs' contribution to maternal and perinatal deaths in Nigeria1-2, 6, coupled with the increasing recognition that providers at lower levels (such as $\mathrm{PHC}$ ) of the health system are a vital point of care for women and children, this project aimed to test the feasibility of CHEWs to detect and manage HDP using alpha methyldopa, as well as $\mathrm{MgSO}_{4}$ administration and referral in selected cases.

This study shows that CHEWs in the intervention sites were able to correctly measure BP and manage HDP. CHEWs at intervention PHC centers were 60 percent more likely to correctly grade hypertension as mild, moderate, or severe, an essential step for effective HDP management of women seeking lower level health care. Those CHEWs were also better able to differentiate HDPs as chronic hypertension, gestational hypertension, or pre-eclampsia. More women attended ANC in the intervention arm, but their BP was not measured, nor urine tested, at every contact. While in resource-poor environments only testing urine for proteinuria for BP over 140/90 may be understandable, there should be no excuse for not measuring BP at every contact. A recent study of facility readiness in sub-Saharan Africa showed particularly poor abilities to manage HDP, indicating that measurement of BP alone may not be adequate for quality care, however ${ }^{26}$.

CHEWs at intervention PHCs also appropriately prescribed alpha methyldopa to pregnant women with moderately severe hypertension. Essential maternal health commodities such as $\mathrm{MgSO}_{4}$ and urine dipstick were more frequently available at intervention facilities, indicating that the intervention affected and improved the supply chain and logistics system. Although facilities in the comparison arm (as are all PHCs in Nigeria) were already mandated by the national task shifting policy to provide a loading dose of $\mathrm{MgSO}_{4}$ and other basic obstetrics services, this intervention has demonstrated that it is possible to integrate an additional service to more holistically manage women with HDPs.

$\mathrm{CHEWs}^{\prime} \mathrm{MgSO}_{4}$ knowledge and use, for women with severe PE/E, improved by 55 percent. Half of all women managed at intervention facilities were administered a loading dose of $\mathrm{MgSO}_{4}$, as opposed to none at comparison sites. This provides the needed evidence and support to begin the empowerment of CHEWs to provide these services more broadly at the PHC level in Nigeria, and in other places with a similar health system structure. A similar study in Nigeria supports $\mathrm{CHEW}$ provision of a loading dose of $\mathrm{MgSO}_{4}$ to women with severe $\mathrm{PE} / \mathrm{E}^{8,11}$.

Maternal and perinatal outcomes were better among women managed at intervention PHCs. The sample sizes in both study groups (40 and 14 women, respectively) were too small for firm conclusions, but these results show potential for this sort of PHC intervention. Where provider skills are enhanced, and essential commodities become more available, health outcomes will consequently improve, as seen in this study, and demonstrated in others $27-29$.

Women's perceptions and experience of their use of PHC services were very encouraging. Women maintain favorable opinions and that their CHEWs provided adequate information, through health talks on various ANC issues, with cordiality by their providers ${ }^{30}$. CHEWs must, however, improve their communication of critical information to clients, to accurately convey clients' severity of condition to them. In some instances CHEWs did not provide adequate information on use of drugs supplied or prescribed. Some women also felt that CHEWs "concealed information" from them about their diagnoses, possibly due to the belief their clients were better not knowing about their condition severity. If women and their families do not know or understand how serious their medical conditions are, and their potential consequences, they may be less likely to urgently seek care.

Local and state governments must fulfill their responsibilities for ensuring essential tools and commodities are available-both at their points of need, and at all times. 


\section{CONCLUSION}

Community health extension workers at primary health care facilities can correctly measure blood pressure, and detect abnormal blood pressure, and thereafter accordingly begin treatment for severe pre-eclampsia and eclampsia and refer cases to higher level facilities for further management. Although challenges remain in ensuring that enough commodities and supplies are continuously available, this study demonstrates how ministries of Health can utilize these essential health workers, and arrest missed opportunities, to detect pre-eclampsia-and potentially, other conditions-and prevent deterioration by providing anti-hypertensives and magnesium sulphate to stabilize women with hypertensive disorders in pregnancy and refer them for appropriate, and often life-saving, continuing treatment.

\section{Recommendations-and Challenges-to Consider for Scale Up}

- Disseminate findings to the Federal Ministry of Health and partners, to consider incorporation within task shifting guidelines.

- The State Ministry of Health should ensure consistent commodities and supplies for managing hypertensive disorders in pregnancy within primary health care.

- The importance of early care seeking in pregnancy and frequent checkups should be emphasized to community members, especially through women's groups.

- Community health extension workers should be updated in importance of information-sharing with women and families.

- Women should be seen as active partners in their health care.

- Referral challenges needs within communities and local government areas need to be discussed. 


\section{REFERENCES}

1. Duley L. 2009. The global impact of pre-eclampsia and eclampsia. Seminars in Perinatology 33(3): 130-137.

2. Khan KS, D Wojdyla, L Say, AM Gülmezoglu, PF Van Look. 2006. WHO analysis of causes of maternal death: a systematic review. Lancet 367(9516): 1066-1074.

3. Abalos E, C Cuesta, AL Grosso, D Chou, L Say. 2013. Global and regional estimates of preeclampsia and eclampsia: a systematic review. Eur J Obstet Gynecol Reprod Biol 170: 1-7.

4. Townsend R, P O'Brien, A Khalil. 2016. Current best practice in the management of hypertensive disorders in pregnancy. Integr Blood Press Control 9: 79-94.

5. World Health Organization. 2007. Maternal mortality in 2005: Estimates developed by WHO, UNICEF, UNFPA and the World Bank. Geneva: World Health Organization.

6. Oladapo OT, OO Adetoro, BA Ekele, C Chama, SJ Etuk et al. 2015. Nigeria Near-miss and Maternal Death Surveillance Network. When getting there is not enough: a nationwide cross-sectional study of 998 maternal deaths and 1451 near-misses in public tertiary hospitals in a low-income country. BJOG 2015. DOI: 10.1111/1471-0528.13450.

7. United Nations Commission for live-saving Commodities for Women and Children. 2012. www.everywomaneverychild.org/resources/un.commission-on-live-saving-commodities

8. Okereke E, B Ahonsi, J Tukur, SM Ishaku, AB Ogini. 2012. Benefits of using magnesium sulphate $\left(\mathrm{MgSO}_{4}\right)$ for eclampsia management and maternal mortality reduction: Lessons from Kano State in Northern Nigeria. BMC Res Notes 5: 421.

9. Euser AG and MJ Cipolla. 2009. Magnesium sulfate treatment for the prevention of eclampsia: A brief review. Stroke 40(4): 1169-1175.

10. Oguntunde $0, Z$ Charyeva, M Cannon, Sambisa et al. 2015. Factors influencing the use of magnesium sulphate in pre-eclampsia/eclampsia management in health facilities in Northern Nigeria: A mixed methods study. BMC Pregnancy and Childbirth 15: 130

11. Tukur J. 2009. The use of magnesium sulphate for the treatment of severe pre-eclampsia and eclampsia. Annals of African Medicine 8(2): 76-80.

12. Kirk KR and I Chattopadhyay. 2015. A systematic review of the treatment and management of preeclampsia and eclampsia in Nigeria. Washington DC: Population Council.

13. Khan TM and A Malik. 2016. Study of Magnesium Sulphate Vs Diazepam in Eclampsia. MedCrave group.

14. Kim YM, N Ansari, A Kols, H Tappis, S Currie, P Zainullah, P Bailey, JV Roosmalen, J Stekelenburg. 2013. Prevention and management of severe pre-eclampsia/eclampsia in Afghanistan. BMC Pregnancy and Childbirth 13: 186

15. Bigdeli M, S Zafar, H Assad, A Ghaffar. 2013. Health System Barriers to Access and Use of Magnesium Sulfate for Women with Severe Pre-Eclampsia and Eclampsia in Pakistan: Evidence for Policy and Practice. PLOS ONE 8(3). 
16. Fujioka A and J Smith. 2011. Prevention and Management of Postpartum Hemorrhage and PreEclampsia/Eclampsia: National Programs in Selected USAID Program-Supported Countries. USAID. www.mchip.net/sites/default/files/2011\%20Progress\%20Report Full\%20Report.pdf

17. English FA, LC Kenny, FP McCarthy FP. 2015. Risk factors and effective management of preeclampsia. Integr Blood Press Control 8: 7-12.

18. World Health Organization 2008. Task shifting: rational redistribution of tasks among health workforce teams: global recommendations and guidelines. Geneva: WHO.

19. World Health Organization. 2012. Optimizing health worker roles to improve access to key maternal and newborn health interventions through task shifting. Geneva: WHO.

20. Ishaku S, B Ahonsi, T Jamilu, A Oginni. 2013. Attrition from care after the critical phase of severe preeclampsia and eclampsia. Insight from an intervention with magnesium sulphate in primary care setting in norther Nigeria. Health Journal 5(9): 1461-1466.

21. Federal Ministry of Health. 2014. Task shifting and task sharing policy for essential health care services in Nigeria. FMoH. www.health.gov.ng/doc/TSTS.pdf Assessed 81/5/2017

22. Sotunsa JO, M Vidler, DO Akeju, MO Osiberu, EO Orenuga, OT Oladapo, R Qureshi, D Sawchuck, OO Adetoro, P Von Dadelszen, OA Dada, CLIP Nigeria Feasibility Working Group. 2016. Community health workers' knowledge and practice in relation to pre-eclampsia in Ogun State, Nigeria: An essential bridge to maternal survival. Reprod Health 13(suppl 2): 108.

23. Warren C, S Ishaku, AB Oginni, G Adoyi, K Kirk, A Dempsey. 2015. Landscape analysis for preeclampsia and eclampsia in Nigeria. Abuja: Population Council. www.endingeclampsia.org/wpcontent/uploads/2017/04/EndingEclampsia-LandscapeReport-Nigeria.pdf. Assessed 30/01/2017

24. World Health Organization. 2011. Recommendations for the prevention and treatment of preeclampsia and eclampsia. WHO Library Cataloguing-in-Publication Data.

25. Calimoutou E, Y Liu, B Mbu. 2016. Compendium of international and national legal frameworks on child marriage. International Bank for Reconstruction and Development and The World Bank.

26. Kanyangarara M, MK Munos, N Walker. 2017. Quality of antenatal care service provision in health facilities across sub-Saharan Africa: Evidence from nationally representative health facility assessments. J Glob Health 7.

27. DeCorby-Watson K, G Mensah, K Bergeron, S Abdi, B Rempel, H Manson. 2018. Effectiveness of capacity building interventions relevant to public health practice: a systematic review. BMC Public Health 18(1): 684.

28. Okoli U, E Eze-Ajoku, M Oludipe, N Speiker, W Ekezie, K Ohiri. 2016. Improving Quality of Care in Primary Health-Care Facilities in Rural Nigeria: Successes and Challenges. Health Serv Res Manag Epidemiol.

29. Uzochukwu B, MD Ughasoro, E Etiaba, C Okwuosa, E Envuladu, OE Onwujekwe. 2015. Health care financing in Nigeria: Implications for achieving universal health coverage. Niger J Clin Pract 18: 437444.

30. Ordinioha B and C Onyenaporo. 2010. Experience with the use of CHEWs in primary care, in a private rural health care institution in South-South Nigeria. Annals of African Medicine 9(4): 240-245. 